\title{
Site Response Analysis of S2 Soil Deposits Focusing on the Effects of Liquefaction and Pore-Pressure Dissipation on the Ground Surface Response Spectrum
}

\author{
Maria Anthi \\ National Technical University of Athens: Ethniko Metsobio Polytechneio \\ NIKOS GEROLYMOS ( $\sim$ gerolymos@gmail.com) \\ NATIONAL TECHNICAL UNIVERSITY OF ATHENS https://orcid.org/0000-0002-3399-561X
}

\section{Research Article}

Keywords: Non-linear ground response analysis, Plasticity model, Soil Profiles with liquefiable layers, Water Flow and Pore pressure dissipation, Kobe 1995 earthquake, Elastic Response of S2 Type Soil Profiles

Posted Date: August 26th, 2021

DOl: https://doi.org/10.21203/rs.3.rs-689776/v1

License: (c) (i) This work is licensed under a Creative Commons Attribution 4.0 International License. Read Full License 


\section{Abstract}

A numerical algorithm for executing non-linear ground response analysis of layered sites is developed, capable of reproducing liquefaction phenomena, considering the simultaneous dissipation of the excess pore water pressure through soil grains. The wave propagation algorithm is based on the plasticity constitutive model for sand Ta-Ger expressed in a one dimensional $p-q$ space form, which exhibits remarkable versatility in representing complex patterns of sand cyclic behavior, such as stiffness decay and decrease in strength due to build-up of pore-water pressure. Its calibration is based on shear modulus reduction and damping curves for drained loading conditions and liquefaction resistance curves for undrained conditions. A detailed presentation of the numerical model formulation is provided, indicating the numerical approach of the wave propagation and consolidation differential equations. The recorded seismic ground response of the Port Island array from Kobe 1995 earthquake is used as a benchmark for testing the validity of model predictions. The model is finally applied to estimate the elastic response spectra at the surface of soil profiles with liquefiable layers (ground type $S_{2}$ ) as per EC8:2004. The investigation study involves the ground response analysis of diverse soil profiles, all including a liquefiable zone, excited with a suite of earthquake motions at their base. The acceleration time histories were extracted from the PEER Ground Motion Database having characteristics compatible with the NGA-estimated response spectrum at the bedrock and with key seismological parameters such as the earthquake magnitude $M_{w}$ and horizontal distance from the fault $R_{J B}$. Two different methods are applied regarding the selection of base excitations: Amplitude scaled records (to match a target response spectrum) and spectral matched records. From the results an idealized response spectrum is deduced in terms of the design spectrum parameters $S, \eta, T_{B}$ and $T_{C}$. It is shown that the idealized ground surface response spectrum is marginally sensitive to method of base excitation selection.

\section{Introduction}

Evaluating soil response to strong earthquake motions, has always been a major issue in earthquake engineering, since it provides essential information in case of constructing an earthquake resistance structure in seismically active areas. Modelling the seismic wave propagation, usually precedes the calculation of the structure response during an earthquake event, since the latter is directly affected by the propagation of seismic waves through the soil deposit. Furthermore, the performance based design method has increasingly drawn the attention of academic community and recent research has been devoted in developing analytical techniques and numerical methods for evaluating the seismic response of soil deposits. Thus, a large number of site response analysis methods have been developed, generally referring to one of the two following methods: the frequency domain analyses (e. g. Schnabel et al. 1972, Asimaki and Kausel 2002, Rathje et al. 2006, Bardet et al. 2000) and the time domain analyses (e. g. Lee and Finn 1978, Gerolymos and Gazetas 2005, Drosos et al. 2012, Modaressi and Foerster, 2000, Tropeano et al. 2016, Hashash et al. 2001, Yang et al. 2004, lai et al. 1990, Elgamal et al. 2003, Pisano and Jeremic 2014).

In this paper, a finite differences algorithm for conducting nonlinear seismic ground response analyses of horizontally layered sites, including liquefaction effects, is developed. Seismic base excitation is assumed to be the result of exclusively vertically polarized $S$ waves, and hence the analysis is reduced to 1-D wave propagation. The constitutive model employed is a downscale version of the plasticity-based Ta-Ger model in mean effective stress $p$ - deviatoric strain $q$ space, initially presented in Anthi and Gerolymos (2021), and deliberately reformulated from its original version (Tasiopoulou \& Gerolymos, 2016 a, b) to accommodate the proposed calibration procedure concerning the drained and undrained response, without re-adjusting model parameters. The developed numerical algorithm involves the 1D consolidation equation to simultaneously account for the generation of excess pore water pressures within sandy layers due to cyclic loading, their distribution and dissipation during and after earthquake shaking and their impact on the transmitted waves. The verification of the proposed algorithm will be held though comparison with the vertical array records obtained at Kobe Port Island, in the 1995 Kobe earthquake. 
The prediction of the response spectra of liquefiable soil deposits is not rigorously investigated in the literature (Gingery et al. 2015) and not adequately covered by the national and global codes, since constructing in such conditions should be generally avoided according to the code guidelines, unless special measures are taken, such as soil reclamation, piles, etc. However, a number of studies evince that such precautions may not be inflicted, on condition that a surface non liquefiable soil layer will be used to mitigate structure settlements (Ishihara et al. 1993, Acacio et al 2001, Cascone and Bouckovalas 1998, Naesgaard et al. 1998, Dashti et al. 2010, Karamitros et al. 2013, Dimitriadi et al. 2017) Thus, estimating the seismic response in prone to liquefaction sites has recently arouse academic interest, since the evaluation of ground response is usually the first step in the calculation of structural response in soil-structure interaction problems. To this direction, as a preliminary application, the proposed model is employed to investigate the calculation of the ground surface elastic response spectra for type $S_{2}$ soil profiles (with liquefiable layers), by analysing the seismic response of an ensemble of idealized, susceptible to liquefaction configurations, submitted to a considerable number of actual seismic records with varying characteristics covering a variety of seismological conditions. Similar to previous studies for nonliquifiable soils (e.g. Rey et al. 2002, Pitilakis et al. 2013, Anastasiadis and Riga 2014), processing of the results leads to the recommendation of an idealized ground surface response spectrum in terms of the design spectrum parameters $S, T_{B}$ and $\mathrm{T}_{\mathrm{C}}$, as per the EC8.

\section{The Model}

\subsection{Constitutive Equations}

The plasticity based constitutive model for sand Ta-Ger is implemented into a numerical algorithm to execute ground response analysis of layered sites. The original formulation is referred to the three dimensional space (Tasiopoulou and Gerolymos, 2016 a, b). Involving an anisotropic plastic flow rule and assuring critical state compatibility among other key features, model is distinguished for its flexibility in reproducing complex patterns of cyclic behavior such as stiffness decay, decrease in strength due to build-up of pore-water pressure., cyclic mobility, densification etc.

The one dimensional version of Ta-Ger model is elaborately introduced in Gerolymos et al. (2018). Expressed in mean effective stress $p$ - deviatoric stress $q$ space, the model acquires the following incremental stress-strain form:

$$
\left[\begin{array}{l}
d p \\
d q
\end{array}\right]=\eta\left[\begin{array}{cc}
K-\frac{-K^{2} M_{s} d}{-K M_{s} d+3 G} \zeta_{a}{ }^{n} & \frac{3 K G d}{-K M_{s} d+3 G} \zeta_{a}{ }^{n} \\
\frac{-3 K G M_{s}}{-K M_{s} d+3 G} \zeta_{a}{ }^{n} & 3 G-\frac{9 G^{2}}{-K M_{s} d+3 G} \zeta_{a}{ }^{n}
\end{array}\right]\left[\begin{array}{l}
d \epsilon_{p} \\
d \epsilon_{q}
\end{array}\right]
$$

1

in which $K$ and $G$ are the elastic (small strain) bulk and shear modulus respectively, $d$ is the ratio of the plastic volumetric strain increment $d \varepsilon_{p}{ }^{p}$ over the plastic deviatoric strain increment $d \varepsilon_{q}{ }^{p}$ and is based on Rowe's dilatancy theory as it depends on the distance of the current stress ratio $q / p$ from the phase transformation line. $M_{p t}$ and $M_{s}$ are the phase transformation and failure stress ratio representing the ultimate strength. Parameter $\zeta_{a}$ (Tasiopoulou and Gerolymos, $2016 \mathrm{a}$ ) is a hysteretic dimensionless quantity that provides the loading and unloading rule and is a function of the BoucWen parameter $\zeta$ (Gerolymos and Gazetas 2005, Gerolymos et al. 2007), while the exponent $n$ controls the rate of transition from the elastic state to the perfectly plastic one. Finally, $\eta$ is inserted as a multiplier of the hardening elastoplastic matrix expressing the dissipated hysteretic energy. 
The analytical formulation of the aforementioned involved parameters is provided in Gerolymos et al. (2018), along with the detailed calibration procedure, based on matching model response with experimental data and empirical correlations. Calibration procedure concerns both drained and undrained conditions of loading. Under drained conditions, the target is to approximate the experimentally documented shear modulus reduction and damping vs cyclic shear strain amplitude curves, while under undrained conditions calibration targets in matching model response with experimental cyclic resistance ratio curves. In Anthi and Gerolymos (2021) a simplified version of the sand model was formulated to simulate clayey soils behavior under cyclic loading, assuming that the development of plastic volumetric strains equals to zero. Different sets of parameters were proposed to better approximate the aforementioned curves published by various investigators. For sand cyclic loading under drained conditions, model was calibrated against the (a) Ishibashi and Zhang (1993), (b) Vucetic and Dobry (1991) and (c) Darendeli et al. (2001) G: $\gamma, \xi: y$ curves, whereas only the first two families of curves were used for the calibration of clayey soils. In what follows, model calibration is based on Ishibashi and Zhang (1993) $G: y, \xi: y$ curves, for sand under drained loading conditions and for clays. Figure 1 depicts the comparison between the proposed relationship results, setting $P I=0$ for sands and $0 \leq P I \leq 15,15 \leq P I \leq 70$ and $70 \leq P I$ for clays, and model predictions executing direct simple shear tests, for various levels of confining pressure.

For undrained loading of sand, a calibration procedure was elaborately presented in Anthi and Gerolymos (2021), based on Idriss and Boulanger $(2004,2008)$ liquefaction resistance reference curve $C R R_{\sigma^{\prime} v=1 \mathrm{~atm}, M w=7.5}$, combined with the following transformation expression to account for isotropic conditions:

$$
C R R_{K_{0} \neq 1}=\left(\frac{1+2 K_{0}}{3}\right) C R R_{K_{0}=1}
$$

2

The comparison with model predictions is depicted in Fig. 2, in terms of the $C R R$ that refers to magnitude 7.5 earthquakes, for confinement pressure equal to 1 atmosphere and lateral earth pressure coefficient $K_{0}$ equal to 1 , against the corrected $S P T$ number. Liquefaction resistance for earthquake magnitudes different than 7.5 was calculated using magnitude scaling factor curves, available in the literature. MSF curves proposed by (a) Idriss (1995) and (b) Andrus and Stokoe (1997) were employed (Gerolymos et al. 2018). In the present work, calibration against Idriss (1995) MSF curve is selected, as is presented in Fig. 3. The NCEER $(1996,1998)$ workshop expression of $K_{\sigma}$ (Youd et al, 2001) is adopted to account for the nonlinearity between $C R R$ and the effective overburden pressure, as Fig. 4 renders for sand relative density $D_{r}=30,40$, 50 and $60 \%$

Calibrated model parameters values for both load conditions of sand and clay can be found in Anthi and Gerolymos (2021).

\subsection{Equation for 1D Consolidation}

The undrained loading of cohesionless saturated soils generates excess pore water pressure, that forces the water to flow through the pores of soil. The water movement changes the volume of the pores, i.e. causes volumetric strains that consequentially lead to effective stresses change. The phenomenon is called soil consolidation and is discussed in this section.

After using some algebra, the principle of water mass conservation inside the pores of soil is expressed as follows:

$$
\operatorname{div}(\vec{v})=\frac{\vartheta \epsilon_{v o l}}{\vartheta t}
$$


Where vis water velocity, $\varepsilon_{v o l}$ stands for the volumetric strain and $t$ for time. By deploying Darcy's law:

$$
\vec{V}=-k \vec{\nabla} h
$$

4

in which $k$ is the soil permeability and $h$ the hydraulic gradient:

$$
h \equiv z+\frac{u_{p}}{\gamma_{w}}
$$

5

with $z$ being the soil depth and $\gamma_{w}$ the water special weight, and assuming that water flow takes place only across the vertical axis, one can obtain the following equation that relates the pore water pressure $u_{p}$ with the soil volumetric strain $\varepsilon_{v o j}$

$$
\frac{k}{\gamma_{w}} \frac{\vartheta^{2} u_{p}(t, z)}{\vartheta z^{2}}=-\frac{\vartheta \epsilon_{v o l(t, z)}}{\vartheta t}
$$

6

which expresses the one dimensional (vertical) soil consolidation.

The boundary condition at the surface of a soil deposit $(z=0)$, which is loaded on its surface with a uniform load $q$ of infinite length, imposes equality between the vertical effective stress at the surface and the external load:

$$
\sigma_{V}^{\prime}(t, 0)=q
$$

7

The boundary condition at the base of the deposit $(z=H)$ depends on the permeability of the underlaying rock. For a permeable base:

$$
\Delta \sigma_{V}^{\prime}(t, H)=q
$$

$8 \mathrm{a}$

while for a non permeable base:

$$
\frac{\vartheta \epsilon_{v o l}(t, H)}{\vartheta t}=0
$$

$8 b$

Assuming a uniform, isotropic, linear elastic soil, Terzaghi's theory provides the analytical solution of the one dimensional consolidation equation (Eq. 6) (Terzaghi 1922, 1925) for a saturated soil column of height $2 H$, permeable on its base with a uniform load $q$ of infinite length on its surface. The isochronous curves of Fig. 5 a provide the consolidation ratio $U$ with the depth, for values of the time factor $T_{v}$ from 0.1 to 1 . It is noted that:

$$
U=1-\frac{\Delta u_{p}}{q}
$$




$$
T_{V}=\frac{k D}{\gamma_{W} H^{2}} t
$$

10

in which $k$ is soil permeability, $D$ is the soil uniaxial compression modulus, $\gamma_{w}$ is the water special weight, $H$ is the half height of the soil profile and $t$ is time

The symbols of Fig. 5, stand for the solution of the system of equations 6 to 8 with the implicit finite differences technique. The convergence is also noted in Fig. $5 \mathrm{~b}$ in terms of the evolution of the dimensionless rate of consolidation:

$$
U(t)=\frac{\delta(t)}{\delta(t=\infty)}
$$

11

against the time factor $T_{v} . U(t)$ expresses the evolution with time of the surface soil settlements $\delta(t)$ in respect of the full soil settlement when consolidation has ended $\delta(t=\infty)$ :

$$
\delta(t=\infty)=2 H q / D
$$

12

It is noted, that the case that was examined with the f.d. algorithm is referred to a $2 H=10 \mathrm{~m}$ deep soil profile, permeable on its base, with $k=10^{-4} \mathrm{~m} / \mathrm{s}, D=30 \mathrm{MPa}$, soil effective special weight $\gamma_{a c t}=10 \mathrm{kN} / \mathrm{m}^{3}$, initial relative density $D_{r 0}=0.5$, surface load $q=200 \mathrm{kPa}$ and water special weight $\gamma_{w}=10 \mathrm{kN} / \mathrm{m}^{3}$. Time step $\Delta t$ was set equal to $5 \cdot 10^{-2} \mathrm{~s}$ and spatial step $h$ equal to $0.1 \mathrm{~m}$.

\subsection{Equation for 1D Wave Propagation}

A numerical algorithm is developed to execute ground response analysis of layered soil profiles subjected to seismic excitation at their base, according to the one-dimensional (vertical) shear wave propagation differential equation:

$$
\rho \frac{\vartheta^{2} u(t, z)}{\vartheta t^{2}}=\frac{\vartheta \tau(t, z)}{\vartheta z}+c \frac{\vartheta^{3} u(t, z)}{\vartheta z^{2} \vartheta t}
$$

13

where $z$ is the depth from surface, $t$ is time, $u$ is the horizontal soil displacement, $\tau$ is soil shear stress, $\rho$ is soil density and $c$ is a viscoelastic constant. The boundary conditions at the base rock $(z=H)$ (rock outcrop motion) and at the top of the soil profile $(z=0)$ are respectively:

$$
\tau(t, H)+c \frac{\vartheta^{2} u(t, H)}{\vartheta z \vartheta t}=\rho_{r} V_{r}\left[\frac{d u(t, H)}{d t}-\frac{d u_{g}(t)}{d t}\right]
$$

14

$$
\frac{d u(t, 0)}{d z}=0
$$

15

The initial conditions are zero displacement and velocity along the soil profile:

$$
u(0, z)=0
$$




$$
\frac{\vartheta u(0, z)}{\vartheta t}=0
$$

17

The numerical approach of the aforementioned problem with the finite difference technique, initially published in Anthi et al. (2017), is extended to simultaneously account for the dissipation of the excess pore water pressure, that is generated within sandy layers due to cyclic loading, according to Eq. 6 . In the absence of an external surface load $q$, boundary conditions 7 and 8 become respectively:

$$
\Delta u_{p}(t, 0)=0
$$

18

at the free ground surface $(z=0)$ which is a permeable boundary, and:

$$
\Delta u_{p}(t, H)=0
$$

$19 a$

for a permeable base rock or:

$$
\frac{\vartheta \epsilon_{V o l}(t, H)}{\vartheta t}=0
$$

$19 b$

if the base rock surface is not permeable. Application of the initial geostatic stresses field along the soil profile is required:

$$
\sigma_{V}{ }^{\prime}(0, z)=\sigma_{V 0}{ }^{\prime}(z)
$$

20

The sets of equations [6] and [18] to [20] that refer to the vertical soil consolidation and [13] to [17] that describe the one dimensional shear wave propagation, are treated with the finite difference method. The procedure followed by the algorithm is that one set of equations is solved first and the obtained results are used for the solution of the second set of equations (in a certain point of time $i$ ). These results in turn, are fed back into the first set of equations to calculate the results in the next point in time $i+1$. Figure 6 gives a schematic depiction of the algorithm procedure. Forward, backward or central finite differences technique is used contextually, resulting in an implicit or an explicit solution method. The alternative solution techniques drawn in Fig. 6 that were examined (f.d., b.d. or c.d. at certain positions) display insignificant deviations, however attention must be given when deciding the size of time and spatial step of the analysis, e.g. if the explicit technique is applied, the discretization should be adequate enough when modelling high soil permeabilities (i.e. $k>1 \mathrm{~m} / \mathrm{s}$ ).

\section{Validation Against The Case History Of Port Island 3.1 Analysis of the Case History}

The wave propagation numerical algorithm is employed to predict the seismic response of the field in the area of Kobe's Port island, in the 1995 earthquake. Model validity is tested against field observations arising from rigorous geotechnical investigation and seismographic instrumentation records, available in the literature (Iwasaki, 1995, 1996). At the northern area of the artificial embankment of Port island, a vertical array of seismometers was installed at $-83 m,-32 m,-16 m$ and $0 \mathrm{~m}$. Table 1 provides the soil characterization of the boring log and the corresponding depths for the borehole where the 
vertical array was installed (Iwasaki, 1995). Ground response analysis was conducted by sectioning the idealized profile in 9 layers. In Anthi ang Gerolymos (2021), the case history of Kobe's Port Island was used as a benchmark to confirm model credibility, assuming undrained response for the saturated soil. In the present work, the analysis is repeated considering consolidation conditions during shaking, as was presented in the previous section.

The compressional and the shear wave velocity distribution with depth, after $P$-S logging that was carried out at the field, is listed in Table 1 (Iwasaki, 1995). The associated shear modulus distribution was estimated according to:

$$
G_{\max }=\rho V_{S}^{2}
$$

21

in which the soil density $\rho$ is according to the saturated specific weight listed in the same table; $20 \mathrm{kN} / \mathrm{m}^{3}$ for sandy soils and $18 \mathrm{kN} / \mathrm{m}^{3}$ for clays.

The standard penetration blow counts of the borehole (after Iwasaki, 1995) are used to calculate the relative density $D_{r}$ for each sandy soil layer, as follows:

$$
D_{r}=\sqrt{\frac{\left(N_{1}\right) 60}{46}}
$$

22

Given the small strain shear modulus distribution according to Eq. 21, the undrained shear strength of the clayey soil layers \# 4 and \# 8 can be estimated according to Weiler (1988), who provided the undrained strength measured in CU triaxial compression tests, depending on the plasticity index and the over-consolidation ratio. For the specified layers an OCR equal to 1 and a Plequal to 25 were assumed.

Permeability $k$ is estimated according to soil type and is assumed $k=10^{-4} \mathrm{~m} / \mathrm{s}$ for the close to surface reclamation soil, $k$ $=10^{-6} \mathrm{~m} / \mathrm{s}$ for sand $/$ gravelly sand and $k=10^{-9} \mathrm{~m} / \mathrm{s}$ for the alluvial clay. Model base at $-83 \mathrm{~m}$ is considered a permeable boundary.

Figures 7, 8 and 9 provide comparison between model results and seismographic instrumentation records. In the same figures, numerical predictions assuming undrained loading conditions for all soil layers except for gravelly layers \# 1and \# 2 at near surface level are included represented with dotted line. It can be concluded, that the convergence with the measured response is broadly sufficient for engineering accuracy, excluding certain cases, while divergence between numerical results considering consolidation or undrained conditions is generally negligible. Specifically, the considerable de-amplification of surface accelerations in Fig. 7 is adequately captured by the model, while the accelerogram at $-16 \mathrm{~m}$ reveals a significant underestimation of the response. The acceleration response spectra of Fig. 8, presents in all three cases an amplification of the low frequency components and a maximum spectral acceleration of about $1 \mathrm{~g}$, for periods between 1 and 1.5 second. The "weak" response of the surface along with the amplification of the low frequency spectral accelerations, evince an intense non-linear response, conceivably accompanied by liquefaction phenomena. The fact that liquefaction must have occurred was pointed out by field observations and measures and later supported by other investigators who analyzed the seismic response of the site. The pore water pressure measurements that took place after the event in a nearby of the seismographic array area, indicated that the sand layer \# 5 was probably liquefied. Iwasaki (1995), supported that surface de amplification was caused by pore water pressure generation at -19m (lower part of \#3 layer in the present study). Ground response analysis executed by Yamazaki et al. (1995), also predicted liquefaction at layer \#5 and at the loose sandy layer \#3, from - 10m to $-16 \mathrm{~m}$. 
Figure 9 portrays the numerical results for the two types of analysis, in terms of distribution with depth of the peak values of acceleration, horizontal displacement, shear stress, shear strain and pore water pressure ratio. Both analyses predict that liquefaction took place to the sandy layers \#3 and \#5, with values of $r_{\text {umax }}$ close to unity, associated with large shear strains. While the response is generally very similar, the simulation of the actual permeability of the surface gravelly layers, instead of considering drained conditions for the same layers that fundamentally prohibit the development of the $r_{u}$, allow the excess pore pressure generated to the lower sandy layers (with $r_{\text {umax }}$ very close to unity) to dissipate up to the surface. This is illustrated in the near to surface maximum $r_{u}$ distribution, where very high $r_{u}$ values are observed, consequently leading to increased shear strains and displacements at the same depths. According to Elgamal et al. (1995), the soil behaved quasi linearly below $-32 \mathrm{~m}$ with limited reduction in stiffness, which is in agreement with the present analysis since displacements are accumulated in shallow depths, above - 30m approximately. Figure 10 shows comparison between the two types of analysis in terms of stress-strain loops at $-10 \mathrm{~m}$ and $-16 \mathrm{~m}$. The left figures (undrained conditions except for layers \#1 and \#2 where drained conditions were considered) are indicative of liquefaction only for the case of gravelly sand $(z=-16 \mathrm{~m})$ with the gravel $(z=-10 \mathrm{~m})$ responding almost linearly, whereas the right figures that correspond to consolidation conditions denote that the surface layer was affected by the dissipated pore pressures.

\subsection{Sensitivity Analysis}

To investigate in more detail how the diffusion of the excess pore water pressure is performed by the model, the seismic response of Port Island site in the 1995 Kobe earthquake is presented in terms of the evolution with time of the mean effective stress, developed in each soil sub-layer. Along with the original configuration as was considered in the previous paragraph (case \#1), three alternative cases are examined (Table 2) for different permeability conditions. Each layer is designated with a different color, according to the first column of Table 2. Each soil profile is subdivided into 83, $1 \mathrm{~m}$-thick sub-layers.

In accordance with the $r_{u, \max }$ distribution of Fig. 9, the highest values of the excess pore pressure were accumulated in layers \#3 and \#5, as is denoted in Fig. 11a by the corresponding curves of $p^{\prime}$ that tend to zero at approximately $5 \mathrm{~s}$ and $10 \mathrm{~s}$ of shaking, respectively. The effective stress of \#2 layer is also decreased to zero, following almost the same pattern with its underlaying layer. The clayey layers \#4 and \#8 undergo practically zero decrease of the effective stress, since no pore pressure is assumed to be generated in the clayey layers and their very small permeability $\left(k=10^{-9}\right)$ prevents the drainage within them. A very modest decrease in $p^{\prime}$ is observer for the deeper sandy layers \#6, \#7 and \#9 most likely due to their significantly high relative density (Table 1 ). Figure 12 provides the evolution of $p^{\prime}$ up to 30 s. Since the earthquake motion lasts only $12 \mathrm{~s}$, after the end of shaking no more pore pressures are generated and the already developed are diffused within the soil layers. According to Fig. 12a, the relatively small permeability of the surface layers \#1 and \#2 causes a slow increase of $p^{\prime}$ of the liquified soil up to $19 \mathrm{~m}$.

In case \#2 of Table 2, a profile with permeability $k=10^{-1}$ for the first two surface layers is examined. Compared to case $\# 1$, it is observed that the response is quite similar up to $12 \mathrm{~s}$ (Fig. 11b), though it is observed that due to the greater permeability of the surface layers the post-earthquake rate of pore-pressure dissipation is more prominent in case \#2. In case \#3, the increased permeability of the deeper layers (\#4 to bottom) allows for the pressures of the liquified sand \#5 to dissipate rapidly within its underlying layers, which is designated by the disturbance of the effective stress propagated to the deeper layers (Figs. 11c and 12c).

It would be interesting to identify, whether the decrease of the effective stress of layers \#1 and \#2 is caused by the pressures generated inside these layers (sandy soil of very low $D_{r}$ ) or they are affected by the dissipation up to the surface of the pressures generated in the underlain liquified layer \#3. Thus, case \#4 is examined, where the first two surface sandy layers are replaced with clayey soil, in which pore pressures are not generated due to cyclic loading. The permeabilities of the soil layers are the same as in case \#1. Figures $11 \mathrm{~d}$ and $12 \mathrm{~d}$ suggest that these layers are affected by the dissipated 
pressures of the underlaying liquefied layer, but the decrease of $p^{\prime}$ is milder. Consequently, it can be deduced that both processes (dissipation and generation) of pore water pressure evolution contribute to the resultant response.

\section{Results}

Figures 19 and 20 depict the ground response analysis results, in terms of the elastic acceleration spectra at the surface, considering all three different drainage conditions (undrained, fully drained, partially drained). Each spectrum is calculated as the mean elastic response spectrum out of 70 analyses (10 soil profiles $\times 7$ accelerograms). The spectra of the base excitations are also drawn (mean values as were presented in Fig. 14). Figure 19 refers to the scaled base excitations and Fig. 20 refers to the spectrum matched input motions. To elucidate the effect of drainage conditions on the frequency content of the response spectrum, the spectral accelerations are normalized with respect to the maximum ground acceleration ( $P S A$ for $T=0$ ). The following generic observations can be drawn: (i) For fully undrained and partially drained (consolidation) conditions only minor differences are observed; the divergence mainly appears when comparing with the drained response. In most cases, the response accounting for consolidation is delimited by the drained and the undrained response. (ii) When fully drained conditions are assumed the maximum spectral accelerations increase compared to the other drainage conditions. (iii) In the high frequency region of the spectra (denoted in figures with shaded area), drained analyses accelerations are higher compared to undrained and consolidation analyses, since excess pore water pressure build up causes de-amplification of the high frequency acceleration components. However, there is a critical period $T$ that appears after the maximum acceleration is observed, at which the drained response degrades more rapidly compared to the undrained (or consolidation) response. Thus, while undrained response exhibits smaller maximum spectral acceleration values compared to the other drainage conditions, it shows greater normalized spectral values for periods greater than $T_{c r}$ This critical period has a mean value of 0.57s for the spectra of Figs. 19 and 0.51s for those of Fig. 20.

Based on the ground response with consolidation, since it is the most representative of the actual field conditions, the normalized mean spectra proceeding from all the seismologic conditions are illustrated in Fig. 21. The response spectra in terms of $S_{e} / a_{g}$ are presented with grey dotted lines and the mean spectrum with solid black line, where $a_{g}$ is the design ground acceleration of ground type $A$ which is equal to $S_{e}$ for $T=0$ at the mean base spectrum. It is observed that the final spectra are very similar both in shape and amplitudes, regardless of the type of the applied input motion (scaled or spectrum matched).

\section{Proposed Elastic Response Spectrum For Ground Type}

\section{PROPOSED ELASTIC RESPONSE SPECTRUM FOR GROUND TYPE $S_{2}$}

According to EC8, the ground motion at a given point on the surface is represented by an elastic ground acceleration response spectrum $S_{e}(T)$, which consists of four branches defined by the following expressions:

$$
0 \leq T \leq T_{B}: S_{e}(T)=a_{g} S\left[1+\frac{T}{T_{B}}\left(\eta A_{C}-1\right)\right]
$$

23.1

$$
T_{B} \leq T \leq T_{C}: S_{e}(T)=a_{g} S \eta A_{C}
$$




$$
T_{C} \leq T \leq T_{D}: S_{e}(T)=a_{g} S \eta A_{C}\left[\frac{T_{C}}{T}\right]
$$

23.3

$$
T_{D} \leq T \leq 4 s: S_{e}(T)=a_{g} S \eta A_{C}\left[\frac{T_{C} T_{D}}{T^{2}}\right]
$$

23.4

where $S_{e}(T)$ is the elastic response spectrum, $T$ is the vibration period of a linear single degree of freedom system, $A_{C}$ is the spectral amplification parameter, equals $2.5, a_{g}$ is the design ground acceleration for ground type $A\left(a_{g}=\gamma_{I} a_{g R}\right), T_{B}$ is the lower limit of the period of the constant spectral acceleration branch, $T_{C}$ is the upper limit of the period of the constant spectral acceleration branch, $T_{D}$ is the value defining the beginning of the constant displacement response range of the spectrum, $S$ is the soil factor and $\eta$ is the damping correction factor ( $\eta=1$ for $5 \%$ viscous damping). The values of $T_{B}, T_{C}$ and $T_{D}$ and of the soil factor $S$ describing the shape of the elastic response spectrum, depend upon the ground type. Specific values are defined for ground types $A, B, C, D$ and $E$, whereas for ground type $S_{2}$ special studies are required to define the seismic action.

In this framework, the mean spectrum of the average spectra of Fig. 21 (mean spectrum of Fig. 21 solid black lines), along with the corresponding mean spectrum at the base, are described via the four-branch curve of Eq. 23 (Fig. 22). The grey solid curve represents the elastic spectrum for ground type $A$, the black solid curve the response of profiles with liquefiable soil layers (ground type $S_{2}$ ) and dotted lines are their linearization according to EC8. The parameters that define the shape of the spectrum for ground types $A$ and $S_{2}$, are described in Fig. 23. The best-fitted values of these parameters, to better approximate the mean response spectra, are listed in Fig. 23. Both approaches regarding the type of the input motion (scaled or spectral matched) converged to a similar soil factor $S$, with a mean value equal to 1.42 . Regarding the key periods, the ratios of ground type $S_{2}$ spectral periods over the corresponding periods for ground type $A$, e.g. $T_{B}\left(S_{2}\right) /$ $T_{B}(A)$ and $T_{C}\left(S_{2}\right) / T_{C}(A)$ equal to 1.3 and 2.8 respectively. Thus, if a reference ground type $A$ spectrum is defined in terms of $A_{C}, T_{B}$ and $T_{C}$, then the response spectrum of ground type $S_{2}$ could be determined.

\section{Conclusions}

A finite difference numerical algorithm was presented, for executing one dimensional ground response analysis of layered sites. The implemented constitutive law is the Ta-Ger model, expressed in the $p$ - $q$ space and appropriately modified to reproduce soil response in both drained and undrained load conditions using a single set of parameters. The calibration was based on attuning model response to the experimentally observed one. Shear modulus reduction and damping curves published by Ishibashi and Zhang (1991) were used to model drained response of sand and undrained response of clay. Under undrained loading condition, the reference liquefaction resistance curve provided by Idriss and Boulanger (2004, 2008) formed the basis of the calibration procedure, along with Idriss (1995) magnitude scaling factors. The foresaid design curves were adequately reproduced by the calibrated model.

Integrating the one dimensional consolidation equation into the developed computer code, the dissipation through soil grains of the excess pore water pressure, that is generated due to cyclic loading of sand, is taken into account. Its numerical solution with the finite difference method was tested against Terzaghi's analytical solution. The accuracy of model predictions in simulating the seismic response of saturated soil was validated against the case history of Port 
island vertical array records, in 1995 Kobe earthquake. The convergence was tested against acceleration time histories at $0 m,-16 m,-32 m$ and $-83 m$ and surface spectrum and proved sufficient for engineering accuracy. The liquefaction of specific sandy layers that was supported by field investigations and previous simulations of the site dynamic response, was confirmed by the present analysis.

Finally, the model was applied to estimate the elastic response spectra at the surface of soil profiles with liquefiable layers. The methodology concerned the ground response analysis of diverse soil profiles, all including a liquefiable zone, excited with a suite of earthquake motions at their base, recorded on rocky formations of ground type $A$. The normalized mean surface response spectrum was linearized to a four-brunch curve, as per the EC8 approach. Specific values for the key parameters that define the shape of the design spectrum were suggested for ground types $S_{2}$ and $A$. Although this work is a preliminary application, it is believed that the presented approach, fleshed out with a bigger and more representative ensemble of soil profiles and base excitations, can form the basis to develop a veridical methodology for estimating the design ground surface response spectrum for soil deposits with potentially liquefiable layers.

\section{Declarations}

\section{ACKNOLEDGEMENT}

This research is co-financed by Greece and the European Union (European Social Fund- ESF) through the Operational Programme «Human Resources Development, Education and Lifelong Learning» in the context of the project

"Strengthening Human Resources Research Potential via Doctorate Research - $2^{\text {nd }}$ Cycle" (MIS-5000432), implemented by the State Scholarships Foundation (IKY).

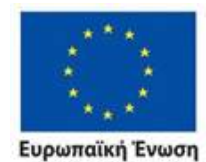

Eupwraïkń Evwơ
European Social Fund
Operational Programme

Human Resources Development,

Education and Lifelong Learning

Co-financed by Greece and the European Union

\section{EEIA}

韭回2014-2020

Data Availability: Available upon request.

Code Availability. Custom Code for Site Response Analysis, Code for ground motion database and seismic hazard assessment available in: PEER Ground Motion Database - PEER Center (berkeley.edu)

\section{References}

1. Abrahamson NA, Silva WJ, Kamai R (2014) Summary of the ASK14 ground motion relation for active crustal regions. Earthquake Spectra 30(3):1025-1055

2. Acacio A, Kobayashi Y, Towhata I, Bautista R, Ishihara K (2001) Subsidence of building foundation resting upon liquefied subsoil case studies and assessment. Soils and Foundations, 2001; 41:111-28

3. Amundsen HA, Thakur V, Emdal A (2015) Comparison of two sample quality assessment methods applied to oedometer test results. Proceedings on XV Panamerican Conference on Soil Mechanics and Geotechnical Engineering, Buenos Aires, November 2015

4. Anastasiadis A, Riga E (2014) Site classification and spectral amplification for seismic code provisions. In: Earthquake Geotechnical Engineering Design. Springer, Cham, pp 23-72

5. Ancheta TD, Darragh RB, Stewart JP, Seyhan E, Silva WJ, Chiou BSJ, Wooddell KE, Graves RW, Kottke AR, Boore DM, Kishida T, Donahue J (May 2013) L. PEER NGA-West2 Database, PEER Report 2013/03. Pacific Earthquake 
Engineering Research Center, Headquarters at the University of California, Berkeley

6. Andrus RD, Stokoe KH (1997) Liquefaction resistance based on shear wave velocity. Proceedings of the NCEER Workshop on Evaluation of Liquefaction Resistance of Soils, National Center for Earthquake Engineering Research, State University of New York at Buffalo, 89-128

7. Anthi M, Gerolymos N (2021) "A Wave Propagation Algorithm for Nonlinear Site Response Analysis of Layered Soil accounting for Liquefaction", Soil Dynamics and Earthquake Engineering, 149 (2021)

8. Anthi M, Tasiopoulou P, Gerolymos N (2017) A plasticity model for 1D soil response analysis. Proceedings on 6th ECCOMAS Thematic Conference on Computational Methods in Structural Dynamics and Earthquake Engineering, Rhodes, Greece, 15-17 June 2017

9. Asimaki D, Kausel E (2002) An equivalent linear algorithm with frequency- and pressuredependent moduli and damping for the seismic analysis of deep sites. Soil Dyn Earthq Eng 22:959-965

10. Boore DM, Stewart JP, Seyhan E, Atkinson GM (2014) NGA-West2 equations for predicting PGA, PGV, and 5\% damped PSA for shallow crustal earthquakes. Earthquake Spectra 30(3):1057-1085

11. Campbell KW, Bozorgnia Y (2014) NGA-West2 ground motion model for the average horizontal components of PGA, PGV, and 5\% damped linear acceleration response spectra. Earthquake Spectra 30(3):1087-1115

12. Cascone E, Bouckovalas GD (1998) Seismic bearing capacity of footings on saturated sand with a clay cap. Proceedings on 11th European Conference on Earthquake Engineering., Paris, September 1998 6-11

13. Chiou BSJ, Youngs RR (2014) Update of the Chiou and Youngs NGA model for the average horizontal component of peak ground motion and response spectra. Earthquake Spectra 30(3):1117-1153

14. Darendeli MB, Stokoe KH, Rathje EM, Roblee CJ (2001) Importance of Confining Pressure on Nonlinear Soil Behavior and Its Impact on Earthquake Response Predictions of Deep Sites. Proceedings of the 15th International Conference on Soil Mechanics and Geotechnical Engineering, August 27-31, Istanbul, Turkey

15. Dashti S, Bray JD, Pestana JM, Riemer M, Wilson D (2010) Mechanisms of Seismically Induced Settlement of Buildings with Shallow Foundations on Liquefiable Soil. J Geotech Geoenviron Eng 2010; 136:151-64

16. Dimitriadi VE, Bouckovalas GD, Papadimitriou AG (2017) Seismic performance of strip foundations on liquefiable soils with a permeable crust. Soil Dyn Earthq Eng 2017; 100:396-409

17. Elgamal AW, Zeghal M, Parra E (1995) Identification and modeling of earthquake ground response, Proc. 1st Int. Conf Earthquake Geotech. Engrg., Tokyo, 3, 1369-1406

18. Gerolymos N, Anthi M, Tasiopoulou P (2018) A plasticity model for 1D site response analysis accounting for liquefaction induced ground movements. Proceedings on the 16th European Conference on Earthquake Engineering, Thessaloniki, Greece, 18-21 June 2018

19. Gerolymos N, Gazetas G (2005) Constitutive model for 1-D cyclic soil behavior applied to seismic analysis of layered deposits. Soils Found 2005; 45(3):147-59

20. Gerolymos N, Gazetas G, Vardoulakis I (2007) A Thermo-poro-visco-plastic shear band model for seismic triggering and evolution of catastrophic landslides. Soils Found 47(1):11-25

21. Gingery JR, Elgamal AW, Bray JD (2015) Response spectra at liquefaction sites during shallow crustal earthquake. Earthquake Spectra 31(4):2325-2349

22. Idriss IM (2014) An NGA-West2 empirical model for estimating the horizontal spectral values generated by shallow crustal earthquakes. Earthquake Spectra 30(3):1155-1177

23. Idriss IM (1995) Seed Memorial Lecture, University of California at Berkeley (I.M. Idriss, personal communication to T.L. Youd, 1997)

24. Idriss IM, Boulanger RW (2004) Semi-empirical procedures for evaluating liquefaction potential during earthquakes, in Proceedings, 11th International Conference on Soil Dynamics and Earthquake Engineering, and 3rd International

Page $13 / 33$ 
Conference on Earthquake Geotechnical Engineering, D. Doolin et al., eds., Stallion Press, Vol. 1, pp. 32-56

25. Idriss IM, Boulanger RW (2008) Soil liquefaction during earthquakes. Monograph MNO-12, Earthquake Engineering Research Institute, Oakland, CA, 2008, pp. 261

26. Ishibashi I, Zhang X (1993) Unified dynamic shear moduli and damping ratios of sand and clay. Soils Found 33(1):182-191

27. Ishihara K, Acacio AA, Towhata I (1993) Liquefaction-induced ground damage in Dagupan in the July 16,1990 Luzon earthquake. Soils and Foundations 1993; 33:133-54.Iwasaki Y. (1995): Geological and geotechnical characteristics of Kobe area and strong ground motion records by 1995 Kobe Earthquake, Soils and Foundations, Special Issue on Geotechnical Aspects of the January 17, 1995 Hyogoken-Nambu Earthquake, 43 (6), 15-20

28. Iwasaki Y, Masaru T (1996) Strong motion records at Kobe Port Island. Special issue of soils and foundations 29-40, Jan 1996, Japanese Geotechnical Society

29. Katsanos El, Sextos AG, Manolis GD (2010) Selection of earthquake ground motion records: A state-of-the-art review from a structural engineering perspective. Soil dynamics earthquake engineering 30(4):157-169

30. Karamitros DK, Bouckovalas GD, Chaloulos YK (2013) Insight into the Seismic Liquefaction Performance of Shallow Foundations. J Geotech Geoenviron Eng 2013; 139:599-607

31. Naesgaard E, Byrne PM, Ven Huizen G (1998) Behaviour of light structures founded on soil "crust" over liquefied ground. Geotech Spec Publ 1998; 75:422-33

32. Pitilakis K, Riga E, Anastasiadis A (2013) New code site classification, amplification factors and normalized response spectra based on a worldwide ground-motion database. Bull Earthq Eng 11(4):925-966

33. Pestana JM, Whittle AJ (1995) Compression model for cohesionless soils. Geotechnique 45(4):611-631

34. Rey J, Faccioli E, Bommer JJ (2002) Derivation of design soil coefficients (S) and response spectral shapes for Eurocode 8 using the European Strong-Motion Database. J Seismolog 6(4):547-555

35. Sextos AG (2014) Selection of Ground Motions for Response History Analysis. Encyclopedia of Earthquake Engineering, 1-1 doi:10.1007/978-3-642-36197-5_114-1

36. Tasiopoulou P, Gerolymos N (2016a) Constitutive modeling of sand: Formulation of a new plasticity approach. Soil Dyn Earthq Eng 82:205-221

37. Tasiopoulou P, Gerolymos N (2016b) Constitutive Modelling of Sand: A Progressive Calibration Procedure accounting for Intrinsic and Stress-Induced Anisotropy. Geotechnique 66(9):1-17

38. Tergazhi K (1922) Der grundbruch an stauwerken and seine verhiltung. Die Wasserkraft 17:687445-687449

39. Terzaghi K. Erdbaumechanik aufbodenphysikalischer Grundlage (Leipzig: Franz Deuticke) 689 (1925)

40. Tsiapas YZ, Bouckovalas GD (2019) Equivalent linear computation of response spectra for liquefiable sites: The spectral interpolation method, Soil Dynamics and Earthquake Engineering 116 (2019) 541-551

41. Vucetic M, Dobry R (1991) Effect of soil plasticity on cyclic response. Journal of Geotechnical Engineering 117(1):89-107

42. Weiler WA (1988) Small strain shear modulus of clay. Proceedings, ASCE conference on earthquake engineering and soil dynamics II: Recent advances in ground motion evaluation, Geotechnical special publication 20, ASCE, New York, pp. 331-335

43. Wils L, Van Impe PO, Haegeman W (2015) One dimensional compression of a crushable sand in dry and wet conditions, Geomechanics from Micro to Macro - Soga et al. (Eds), 2015 Taylor \& Francis Group, London, ISBN 9781-138-02707-7

44. Yamazaki F, Ansary MA, Towhata I (1995) Application of a dynamic effective stress model at a reclaimed site during the Great Hanshin earthquake, 1995, Proc. 1st Int. Conf. Earthquake Geotech. Engrg., Tokyo, 1, 591-597 
45. Youd TL, Idriss IM, Andrus RD, Arango I, Castro G, Christian JT et al (2001) Liquefaction resistance of soils: Summary report from the 1996 NCEER and NCEER/NSF workshops on evaluation of liquefaction resistance of soils. Journal of Geotechnical and Geoenvironmental Engineering, ASCE 2001.127:817-833, October 2001

46. Zafeirakos A, Gerolymos N (2013) On the Seismic Response of Under-Designed Caisson Foundations. Bull Earthq Eng 11(5):1337-1372

\section{Tables}

Table 1. Discretization of soil layers: velocity of P and S waves by PS-logging [boring log at the site, K.P.: Kobe Peil (Reference level for marine work in Kobe)] and standard penetration blow counts (N values) (Iwasaki, 1995). Calculated / estimated values of relative density Dr, elastic shear modulus Gmax, undrained shear strength Su, saturated specific weight ysat and permeability k are also listed (*reclamation soil: sandy gravel soil of high permeability and very low estimated strength).

\begin{tabular}{|c|c|c|c|c|c|c|c|c|c|c|}
\hline $\begin{array}{l}\text { Layer } \\
\#\end{array}$ & $\begin{array}{l}\text { Depth } \\
\text { (m) }\end{array}$ & $\begin{array}{l}\text { Soil } \\
\text { Type }\end{array}$ & $\begin{array}{l}\mathrm{Vp} \\
(\mathrm{m} / \mathrm{s})\end{array}$ & $\begin{array}{l}\text { Vs } \\
(\mathrm{m} / \mathrm{s})\end{array}$ & (N1)60 & $\mathrm{Dr}$ & $\operatorname{Gmax}(\mathrm{KPa})$ & $\mathrm{Su}(\mathrm{KPa})$ & ysat (KN/m3) & $\mathrm{k}(\mathrm{m} / \mathrm{s})$ \\
\hline 1 & $0-5$ & Gravel* & 305 & 170 & 4 & 0.29 & 57.8 & - & 20 & $10-4$ \\
\hline 2 & $5-13$ & Gravel* & 780 & 210 & 4 & 0.29 & 88.2 & - & 20 & $10-4$ \\
\hline 3 & $13-19$ & $\begin{array}{l}\text { Gravelly } \\
\text { sand }\end{array}$ & 1480 & 210 & 6 & 0.36 & 88.2 & - & 20 & $10-4$ \\
\hline 4 & $19-27$ & $\begin{array}{l}\text { Alluvial } \\
\text { clay }\end{array}$ & 1180 & 180 & - & - & 58.32 & 82 & 18 & $10-9$ \\
\hline 5 & $27-33$ & Sand & 1350 & 245 & 25 & 0.74 & 120.1 & - & 20 & $10-6$ \\
\hline 6 & $33-50$ & $\begin{array}{l}\text { Sand / } \\
\text { Gravelly } \\
\text { Sand }\end{array}$ & 1530 & 305 & 40 & 0.93 & 186.1 & - & 20 & $10-6$ \\
\hline 7 & $50-61$ & Sand & 1610 & 350 & 45 & 0.99 & 245.0 & - & 20 & $10-6$ \\
\hline 8 & $61-79$ & $\begin{array}{l}\text { Stiff } \\
\text { alluvial } \\
\text { clay }\end{array}$ & 1610 & 303 & - & - & 165.3 & 233 & 18 & $10-9$ \\
\hline 9 & $79-83$ & $\begin{array}{l}\text { Gravelly } \\
\text { sand }\end{array}$ & 2000 & 320 & 60 & 1.00 & 204.8 & - & 20 & $10-6$ \\
\hline
\end{tabular}

Table 2. Examined alternative soil profiles of the Port Island site in the 1995 Kobe earthquake.

\begin{tabular}{|c|c|c|c|c|c|c|c|c|c|}
\hline \multirow{2}{*}{ Layer \# } & \multirow{2}{*}{$\begin{array}{c}\text { Depth from } \\
\text { surface }(\mathrm{m})\end{array}$} & \multicolumn{2}{|c|}{ case $\# 1$} & \multicolumn{2}{c|}{ case $\# 2$} & \multicolumn{2}{c|}{ case \#3 } & \multicolumn{3}{c|}{ case \#4 } \\
\cline { 3 - 10 } & & soil type & $\mathrm{k}(\mathrm{m} / \mathrm{s})$ & soil type & $\mathrm{k}(\mathrm{m} / \mathrm{s})$ & soil type & $\mathrm{k}(\mathrm{m} / \mathrm{s})$ & soil type & $\mathrm{k}(\mathrm{m} / \mathrm{s})$ \\
\hline $\mathbf{1}$ & $0-5$ & sand & $10^{-4}$ & sand & $10^{-1}$ & sand & $10^{-1}$ & clay & $10^{-4}$ \\
\hline $\mathbf{2}$ & $5-13$ & sand & $10^{-4}$ & sand & $10^{-1}$ & sand & $10^{-1}$ & clay & $10^{-4}$ \\
\hline $\mathbf{3}$ & $13-19$ & sand & $10^{-4}$ & sand & $10^{-4}$ & sand & $10^{-4}$ & sand & $10^{-4}$ \\
\hline 4 & $19-27$ & clay & $10^{-9}$ & clay & $10^{-9}$ & clay & $10^{-6}$ & clay & $10^{-9}$ \\
\hline $\mathbf{5}$ & $27-33$ & sand & $10^{-6}$ & sand & $10^{-6}$ & sand & $10^{-4}$ & sand & $10^{-6}$ \\
\hline 6 & $33-50$ & sand & $10^{-6}$ & sand & $10^{-6}$ & sand & $10^{-4}$ & sand & $10^{-6}$ \\
\hline 7 & $50-61$ & sand & $10^{-6}$ & sand & $10^{-6}$ & sand & $10^{-4}$ & sand & $10^{-6}$ \\
\hline $\mathbf{8}$ & $61-79$ & clay & $10^{-9}$ & clay & $10^{-9}$ & clay & $10^{-6}$ & clay & $10^{-9}$ \\
\hline $\mathbf{9}$ & $79-83$ & sand & $10^{-6}$ & sand & $10^{-6}$ & sand & $10^{-4}$ & sand & $10^{-6}$ \\
\hline
\end{tabular}


Table 3. Examined potentially liquefiable soil profiles; parametric investigation regarding the surrounding soil, the liquefiable sandy layer and the top and bottom clayey layers

\begin{tabular}{|c|c|c|c|c|c|c|c|c|c|c|c|}
\hline & $\begin{array}{l}\text { Soil } \\
\text { Profile }\end{array}$ & \# 1 & \# 2 & \# 3 & \# 4 & \# 5 & $\# 6$ & $\# 7$ & $\# 8$ & $\# 9$ & \# 10 \\
\hline \multirow{5}{*}{$\begin{array}{l}\text { surrounding } \\
\text { soil }\end{array}$} & Type & sand & & & & & clay & & & & \\
\hline & $\mathrm{H}(\mathrm{m})$ & 15 & 20 & 25 & 30 & 35 & 15 & 20 & 25 & 30 & 35 \\
\hline & $\operatorname{Dr}[\%]$ & 40 & 50 & 60 & 70 & 80 & - & - & - & - & - \\
\hline & $\mathrm{Su}[\mathrm{kPa}]$ & - & - & - & - & - & $40+5 z$ & $45+5 z$ & $50+5 z$ & $55+5 z$ & $60+5 z$ \\
\hline & $\mathrm{k}[\mathrm{m} / \mathrm{s}]$ & $\begin{array}{l}10- \\
3\end{array}$ & $\begin{array}{l}10- \\
3\end{array}$ & $\begin{array}{l}10- \\
4\end{array}$ & $\begin{array}{l}10- \\
4\end{array}$ & $\begin{array}{l}10- \\
4\end{array}$ & $10-6$ & & & & \\
\hline \multirow{2}{*}{$\begin{array}{l}\text { liquefiable layer: } \\
\mathrm{Dr}=30 \%, \mathrm{k}=10-3 \mathrm{~m} / \mathrm{s}\end{array}$} & $\mathrm{hL}[\mathrm{m}]$ & 1.5 & 5 & 1.5 & 5 & 7 & 1.5 & 5 & 1.5 & 5 & 7 \\
\hline & $\mathrm{hf}[\mathrm{m}]$ & 2 & 2 & 7 & 7 & 7 & 2 & 2 & 7 & 7 & 7 \\
\hline $\begin{array}{l}\text { surface clay: } \\
h=2 m, k=10-6 m / s\end{array}$ & $\mathrm{Su}[\mathrm{kPa}]$ & 40 & 45 & 50 & 55 & 60 & 40 & 45 & 50 & 55 & 60 \\
\hline $\begin{array}{l}\text { bottom clay: } \\
h=2 \mathrm{~m}, \mathrm{k}=10-6 \mathrm{~m} / \mathrm{s}\end{array}$ & $\mathrm{Su}[\mathrm{kPa}]$ & 105 & 135 & 165 & 195 & 225 & 105 & 135 & 165 & 195 & 225 \\
\hline
\end{tabular}

Figures 

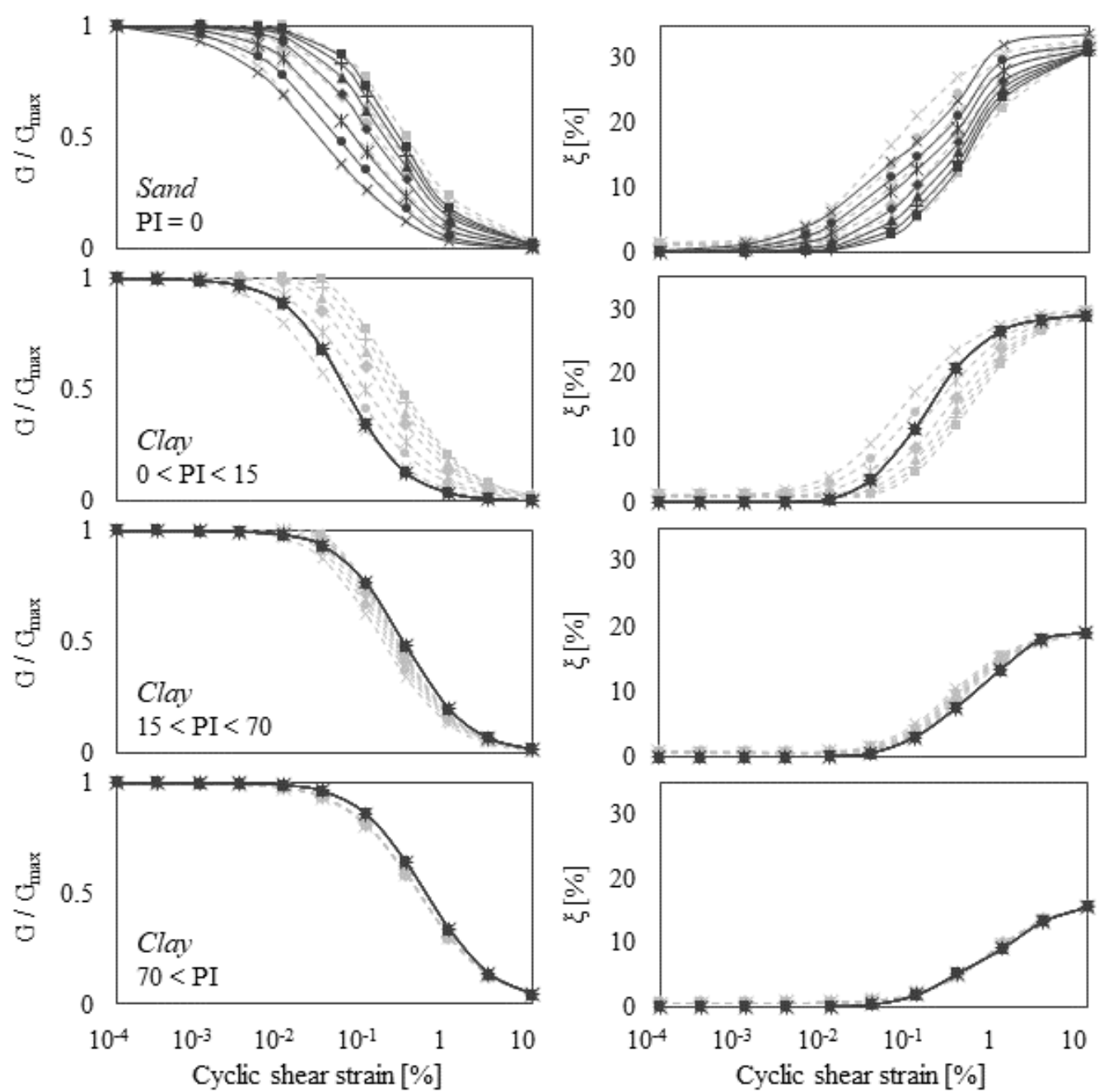

Ishibashi et. al (1993)

\begin{tabular}{|c|c|c|c|c|c|c|}
\hline$---x--20$ & -50 & $---\frac{*}{-10}--100$ & $-\cdots--200$ & $---1 x^{-}-300$ & --+--400 & $---1+-500$ \\
\hline 30 & $\bullet$ & 米 100 & $\longrightarrow 200$ & $\longrightarrow-300$ & -400 & 500 \\
\hline
\end{tabular}

Figure 1

Approximation of the Ishibashi \& Zhang (1993) shear modulus and damping curves for sand (PI=0) and clay (0 


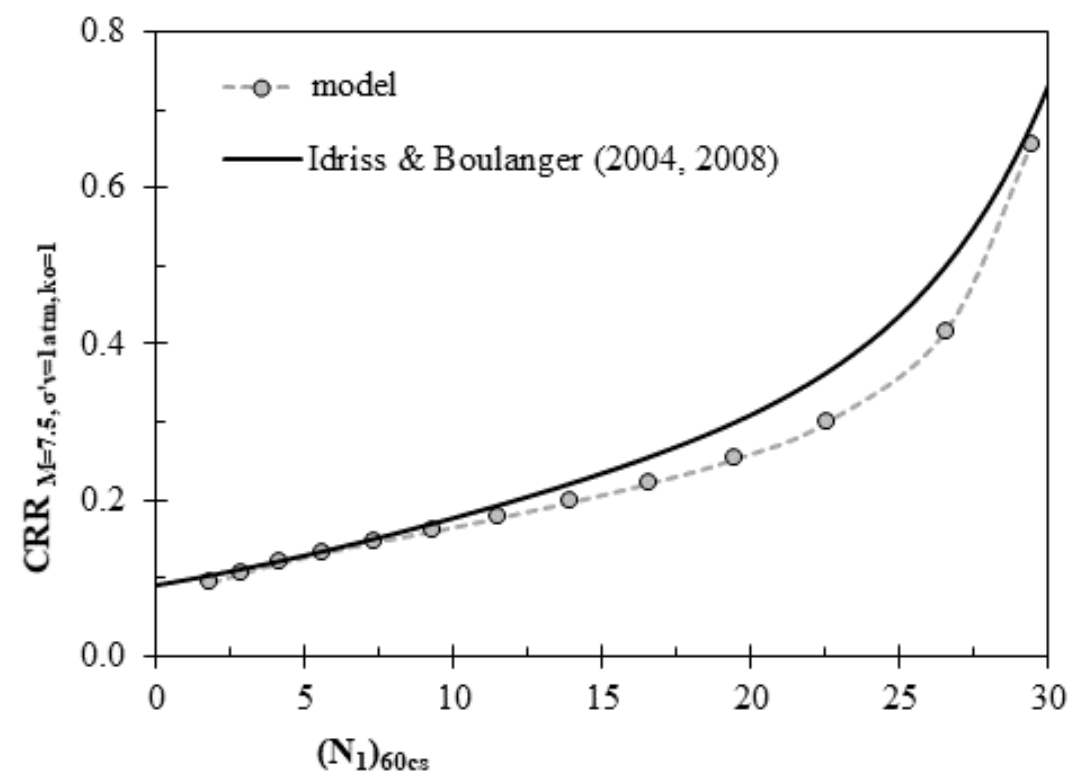

Figure 2

Model predictions vs suggested by Idriss and Boulanger $(2004,2008)$ reference cyclic resistance ratio ( $M w=7.5$, $\left.\sigma^{\prime} v=1 \mathrm{~atm}\right)$, transformed according to Equation [2] to account for isotropic consolidation conditions, against the corrected SPT number.

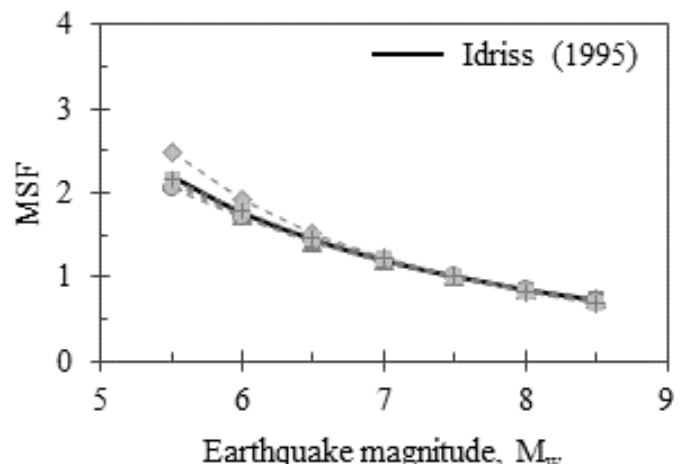

$$
\begin{aligned}
& \text { model }
\end{aligned}
$$

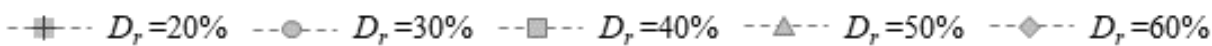

\section{Figure 3}

Comparison between model predictions and proposed by Idriss (1995) magnitude scaling factors as a function of the earthquake magnitude in order to trigger liquefaction for selected values of the relative density; $\mathrm{Dr}=20 \%, 30 \%, 40 \%, 50 \%$ and $60 \%$ 


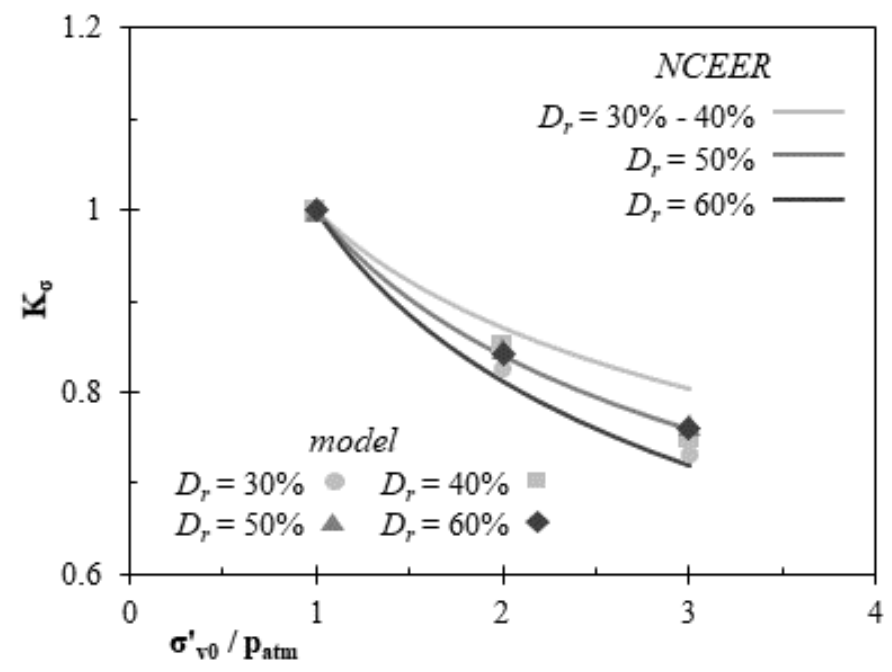

\section{Figure 4}

Comparison of Ko factors derived from the calibrated model for selected values of the relative density $(\mathrm{Dr}=30 \%, 40 \%$, $50 \%, 60 \%)$ for liquefaction triggering in 15 uniform loading cycles. Comparison is given with the expressions recommended by the 1996 NCEER/1998 NCEER/NSF workshops.
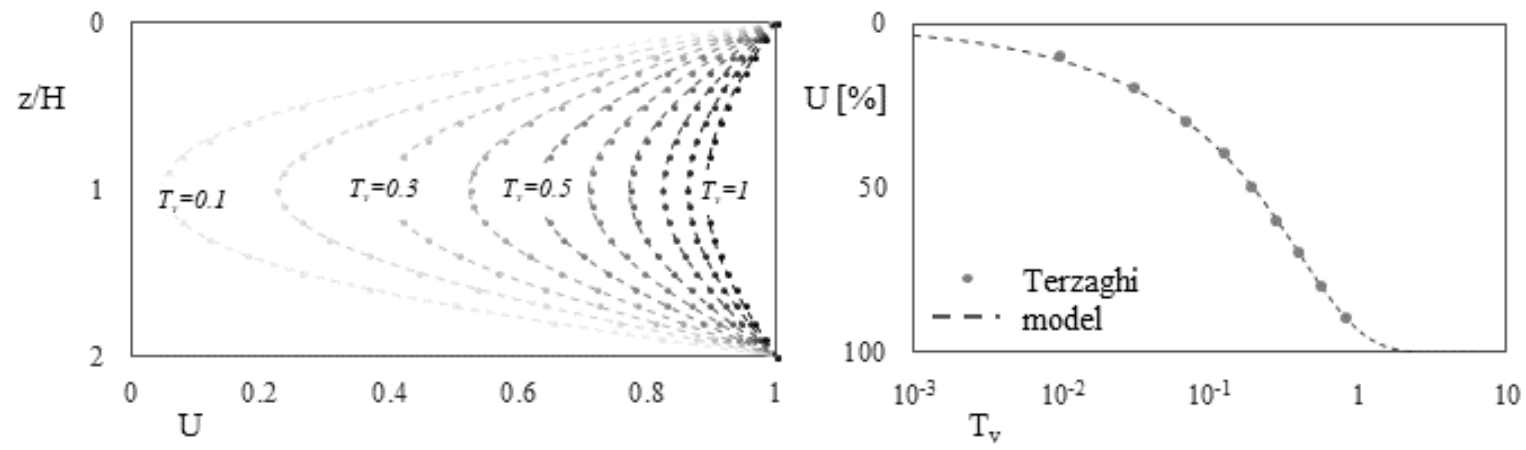

\section{Figure 5}

Solution of the 1-dimensional vertical consolidation equation of soil using the finite difference method, against Terzaghi's analytical solution; (a) [left] Isochronous curves of consolidation ratio U distribution with depth, (b) [right] Consolidation ratio $U$ evolution with time 
input seismic motion at the base,

boundary cond. (eq. 14,15), initial cond. (eq. 16,17)

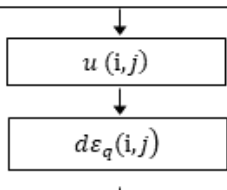

constitutive relationship (eq.1) \& consolidation eq. 6

boundary cond. (eq. 18,19), initial cond. (eq.20)

(for the term: $\frac{\vartheta^{2} u_{p}(t, z)}{\vartheta z^{2}}$ of eq. $6 \rightarrow$ c. d. at position $x_{j}$ )

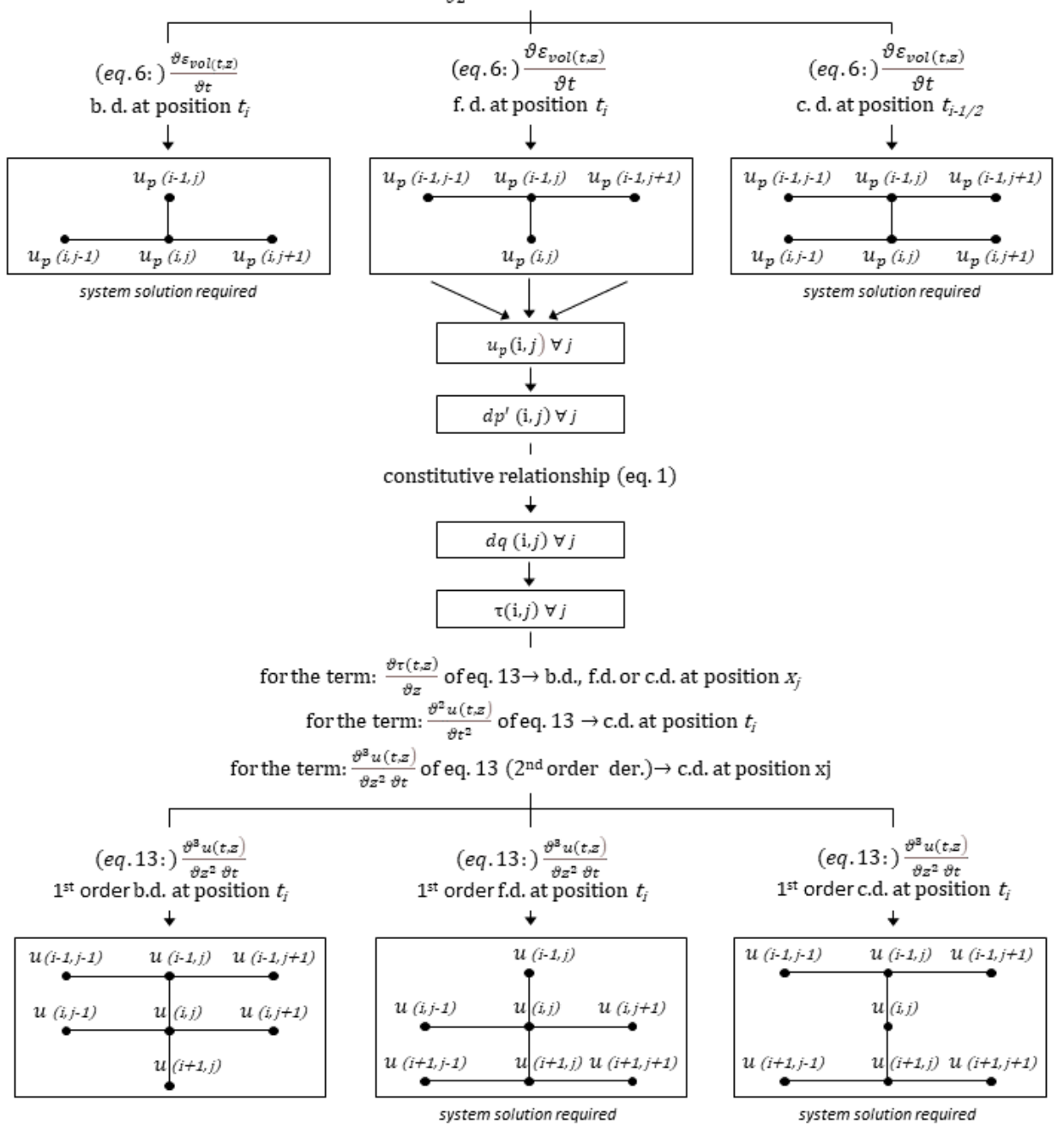

Figure 6

Wave propagation algorithm flowchart 

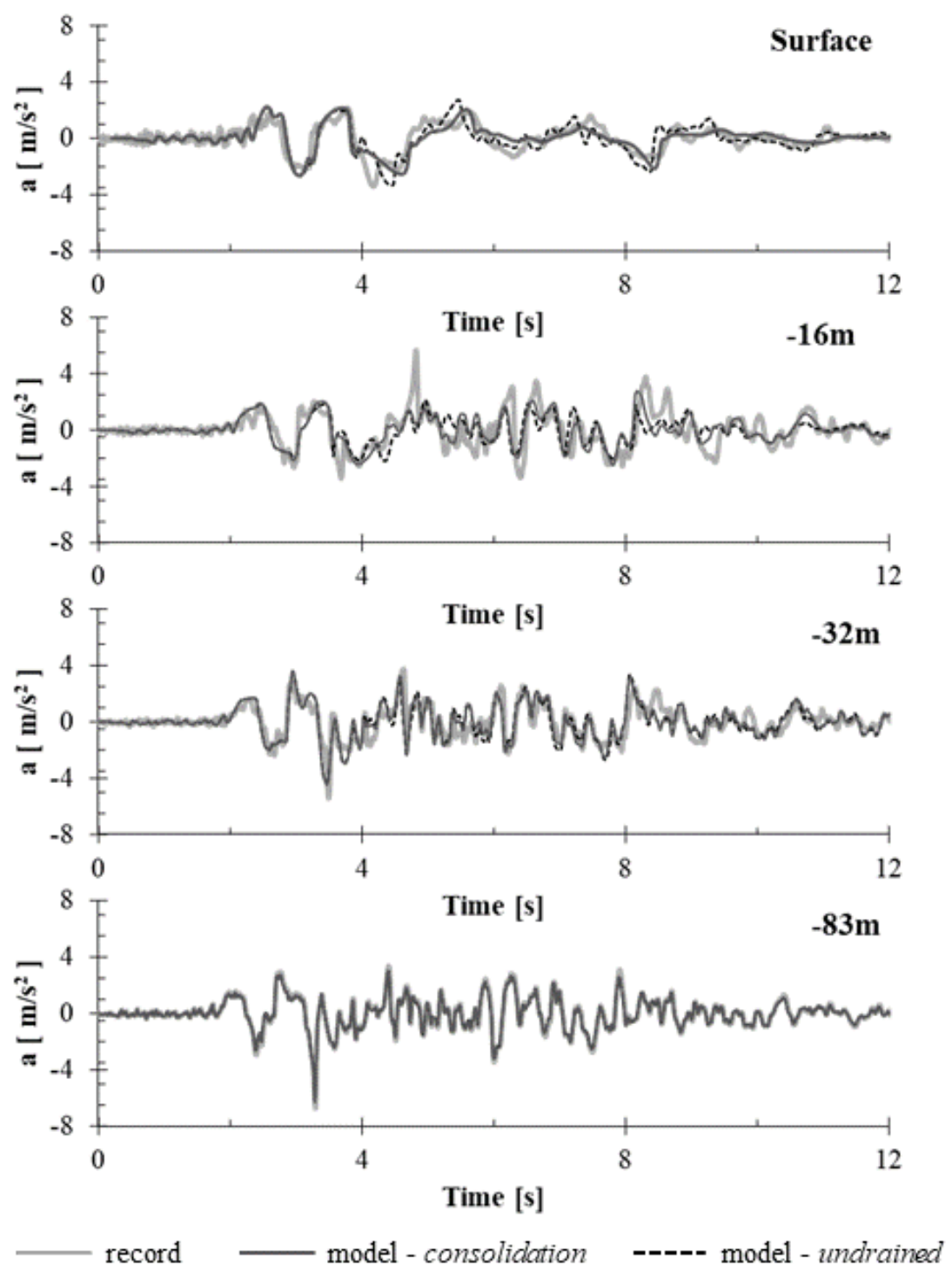

Figure 7

Recorded motions of NS component at Kobe Port Island against model predictions assuming consolidation conditions and undrained loading conditions during shaking, at the surface, $-16 m-32 m$ and $-83 m$

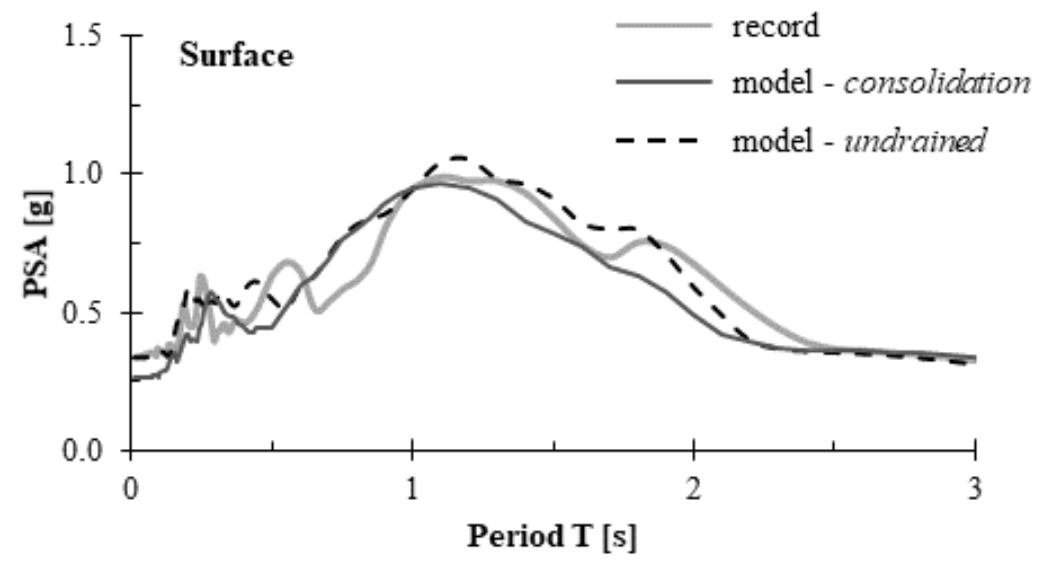




\section{Figure 8}

Distributions with depth of the peak values of acceleration, pore pressure ratio, shear strain, shear stress and displacement, predicted assuming consolidation conditions and undrained loading conditions during shaking (base excitation: NS component at Kobe Port Island).
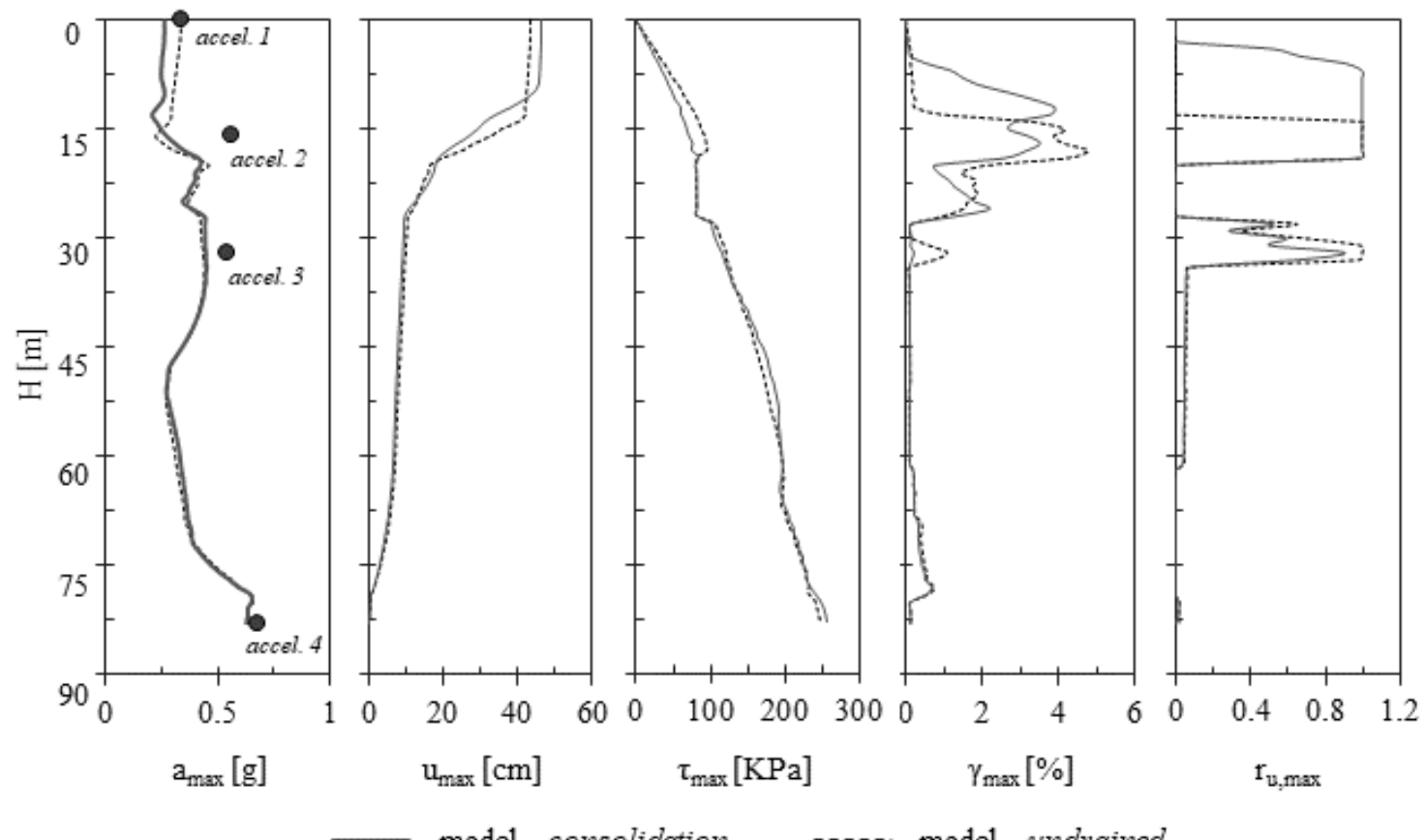

model - consolidation

model - undrained

\section{Figure 9}

Shear stress - strain loops computed with Ta- Ger model at $z=-10 m$ and $z=-16 m$ assuming consolidation conditions [right] and undrained loading conditions during shaking [left] (base excitation: NS component at Kobe Port Island). 

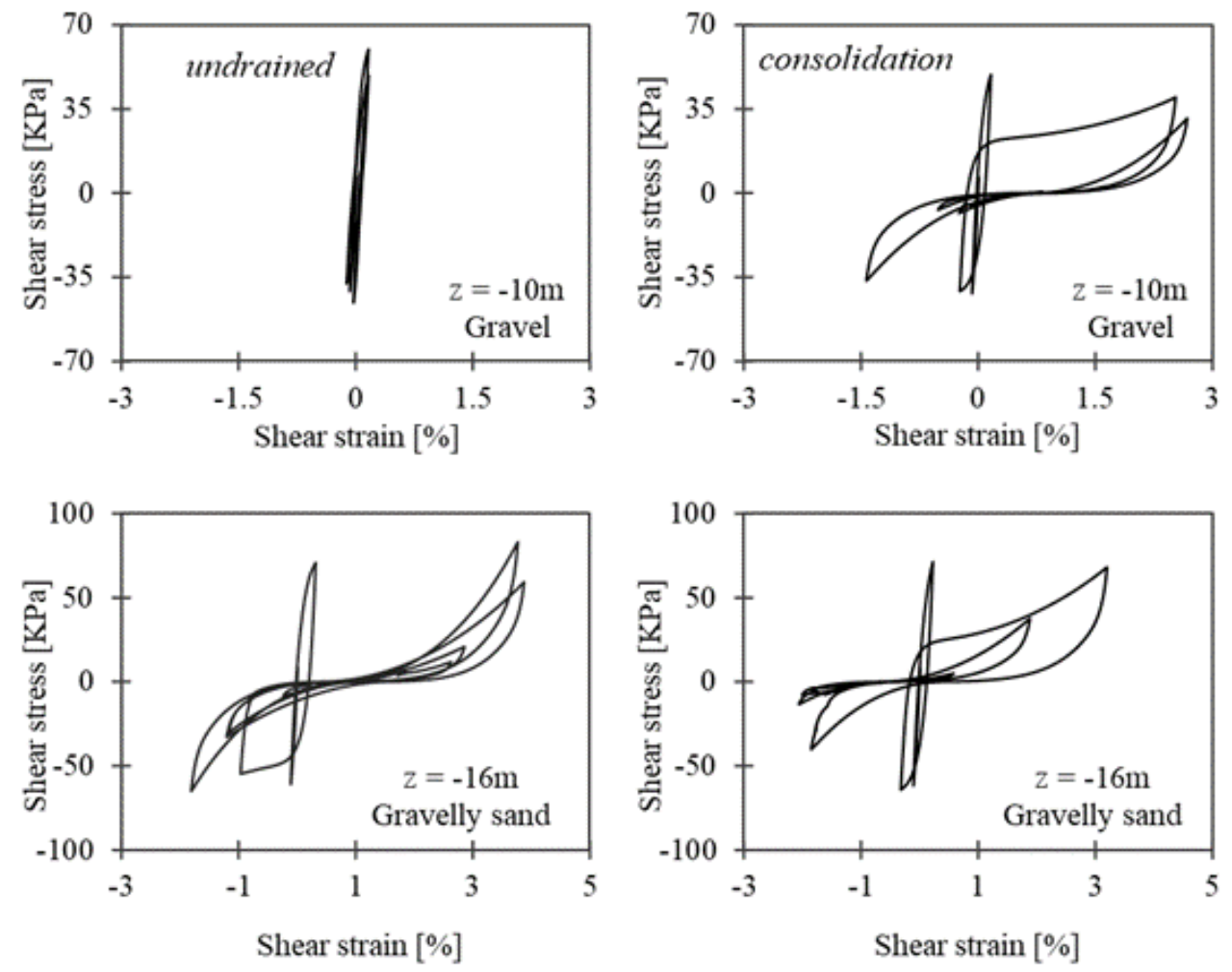

Figure 10

Evolution of the mean effective stress $p^{\prime}$ for the four profiles listed in Table 2, for 12 s of earthquake shaking 


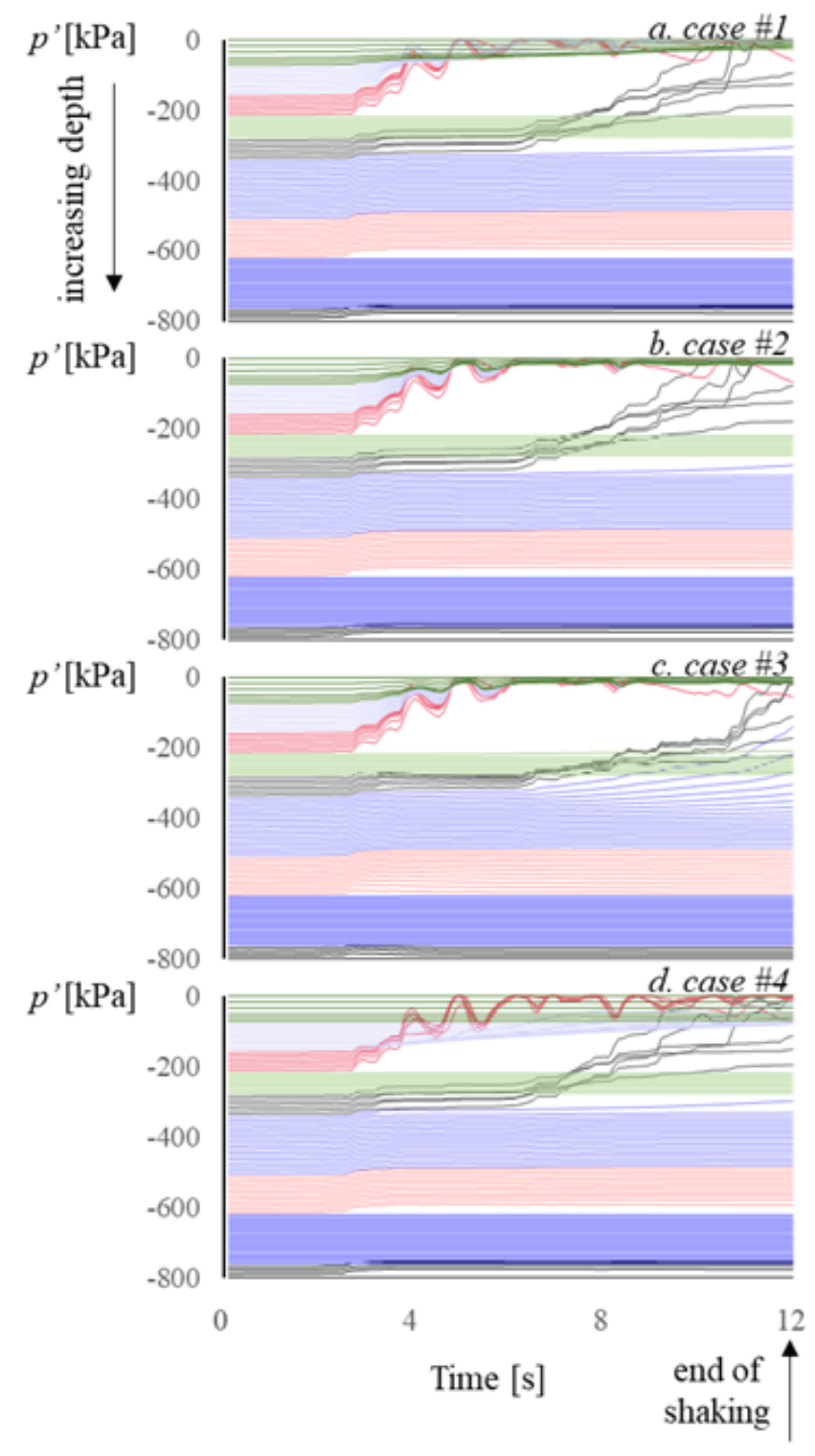

Figure 11

Evolution of the mean effective stress $p^{\prime}$ for the four profiles listed in Table 2 extended to 30 s, for $12 s$ of earthquake shaking 


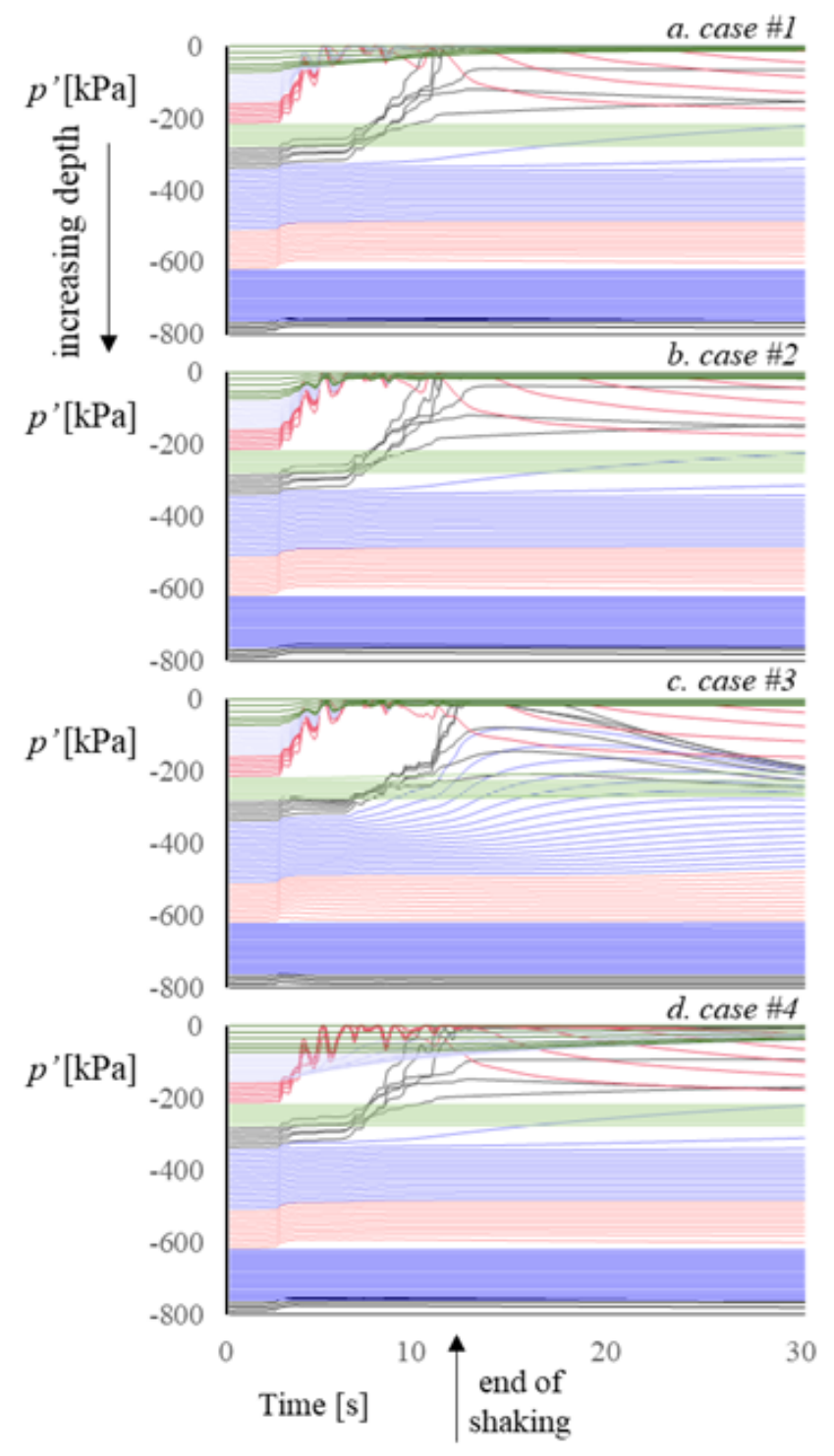

Figure 12

Indicative recorded earthquake motions that were used as base excitations ( data from Peer Ground Motion Database ). 


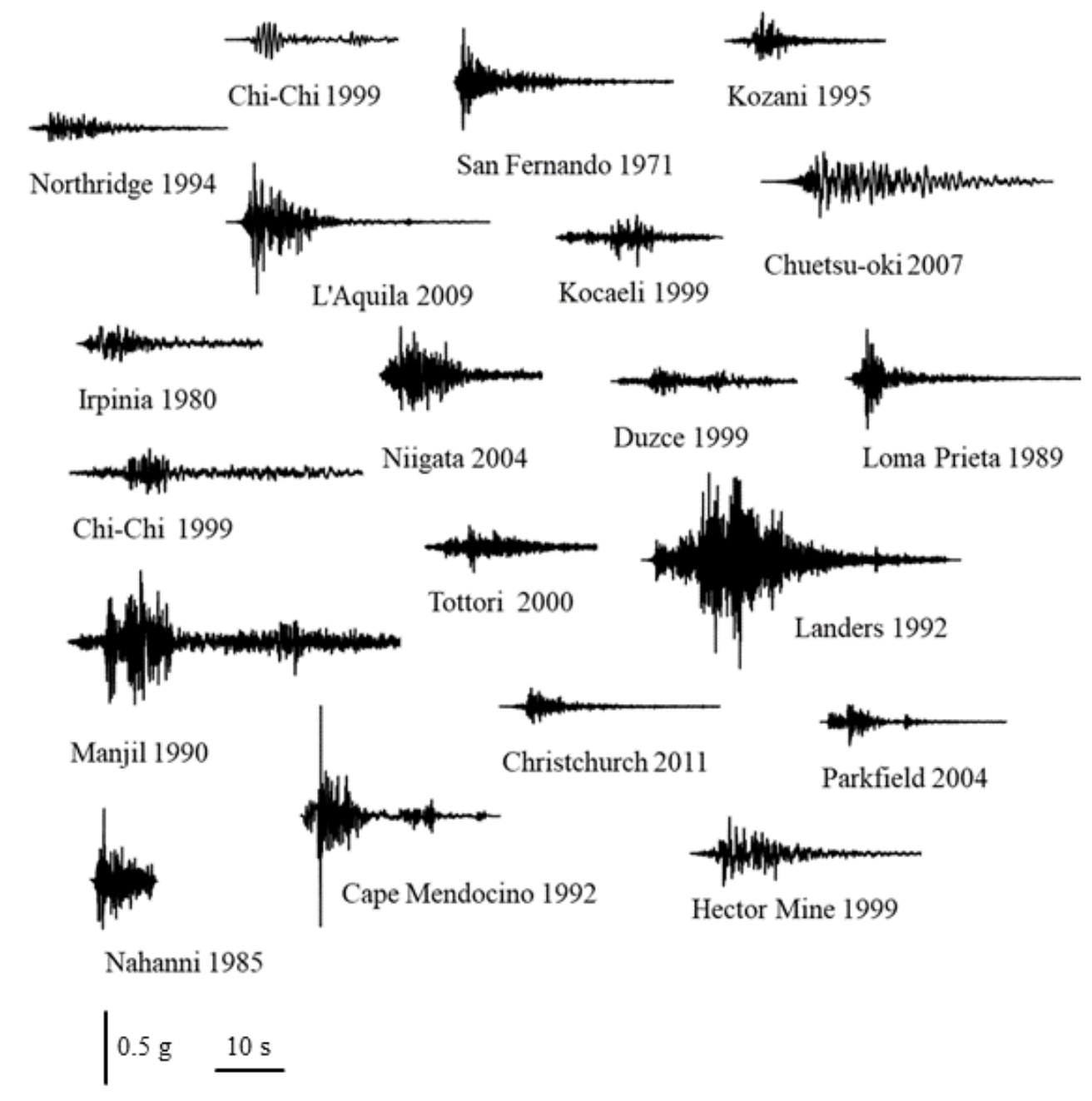

Figure 13

Target spectra, derived via the NGA - West2 attenuation relationships, calculated for 9 (Mw, RJB ) combinations in comparison with acceleration response spectra ( mean values) of the recorded earthquake motions that were used as base excitations at the ground response analyses. 

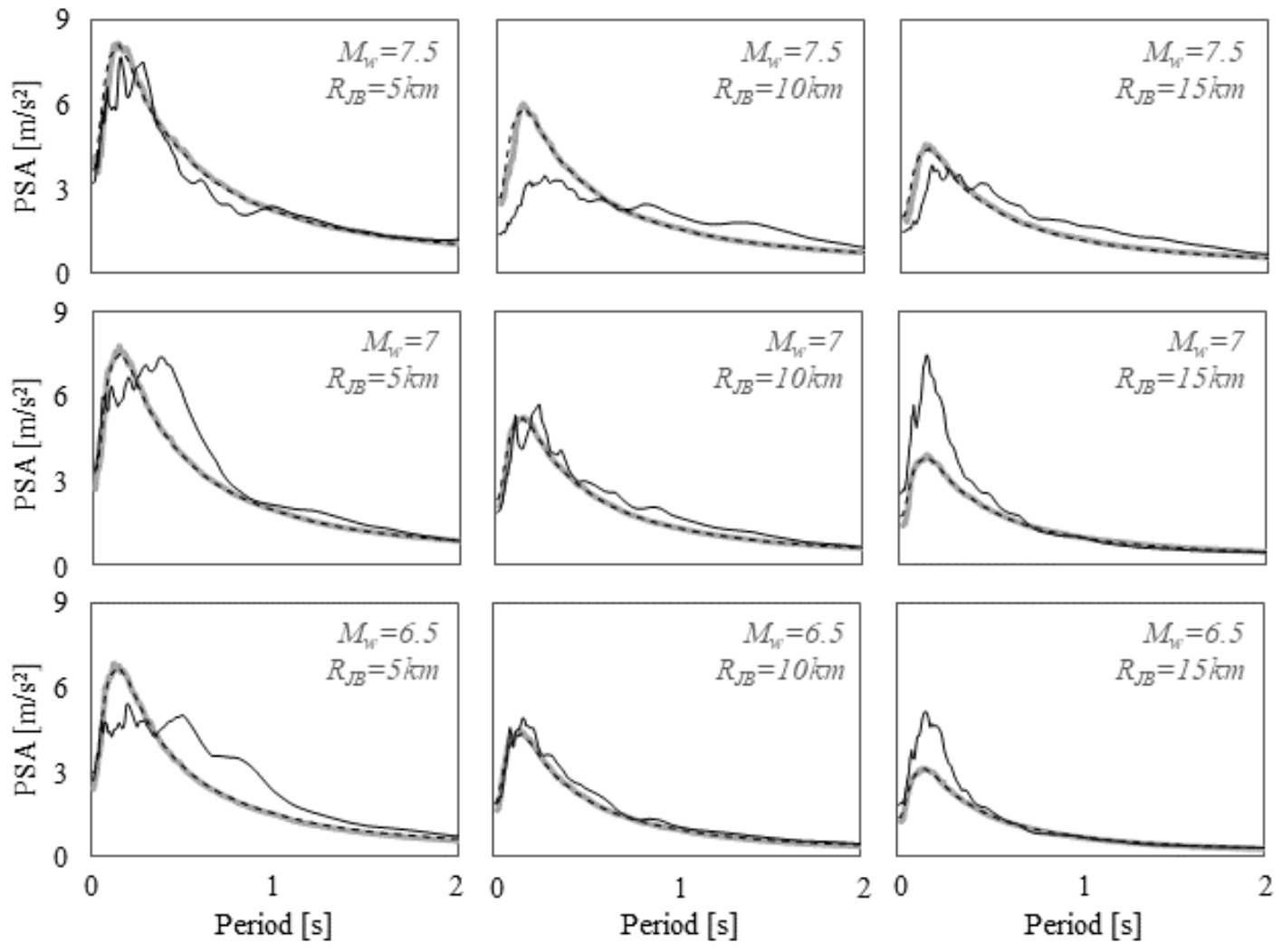

target base spectrum

mean base spectrum (scaled earthquake motions)

mean base spectrum (spectral matched earthquake motions)

Figure 14

Soil profile and Vs distribution with depth used in the example analysis. (profile \#4 in Table 3) 


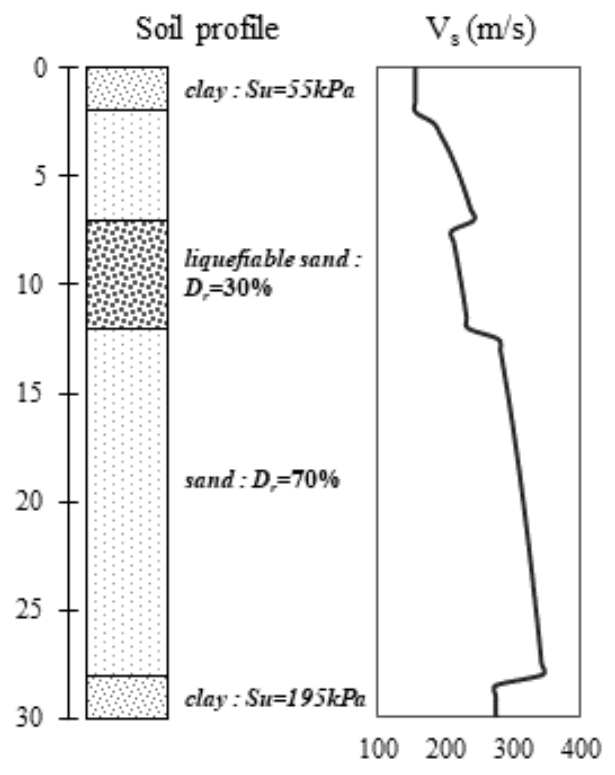

Figure 15

Soil profile and Vs distribution with depth used in the example analysis. (profile \#4 in Table 3) 

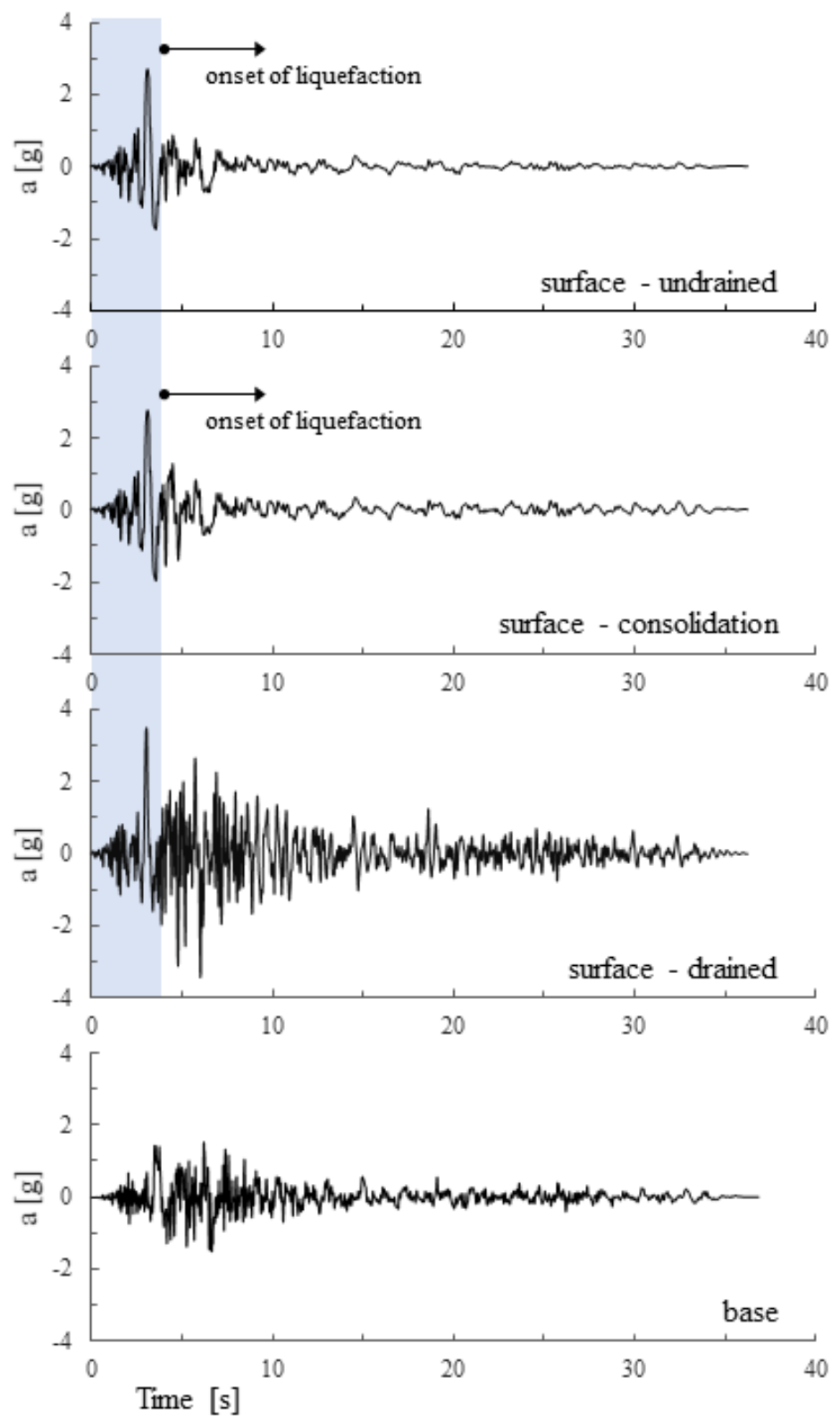

\section{Figure 16}

Ground response analyses results in terms of the computed acceleration time history, considering drained, undrained and consolidation conditions during shaking. Base motion used in the example analysis: Irpinia Italy 1980, Station name Bagnoli Irpinio, Magnitude 6.9 (scaling factor 1.18) 


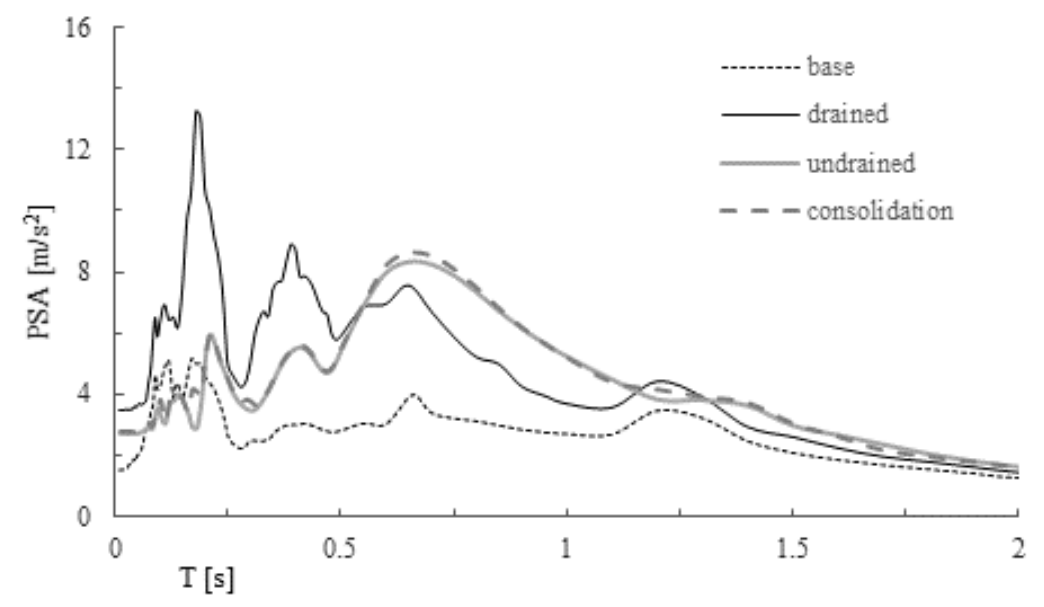

Figure 17

Ground surface elastic response spectra predicted by the example analysis considering drained, undrained and consolidation conditions during shaking. Base motion: Irpinia Italy 1980, Station name Bagnoli Irpinio, Magnitude 6.9 (scaling factor 1.18)

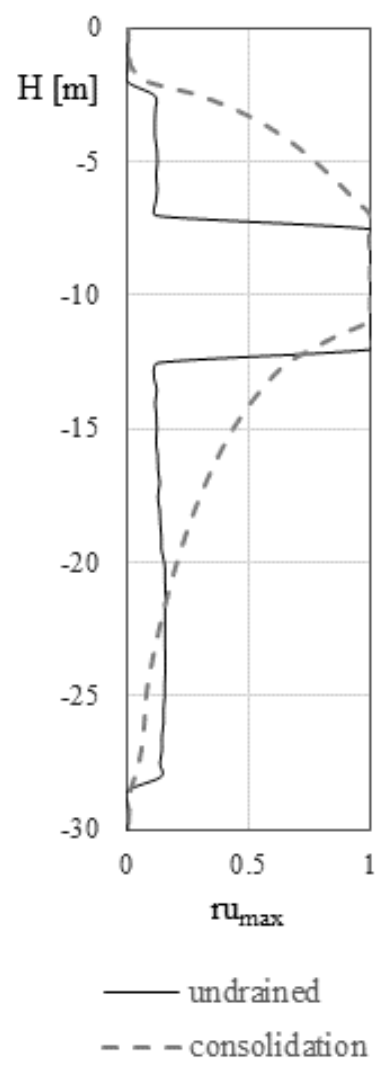

Figure 18 
Profile of the maximum excess pore water pressure ratio rumax distribution with depth predicted by the example analysis considering undrained and consolidation conditions during shaking
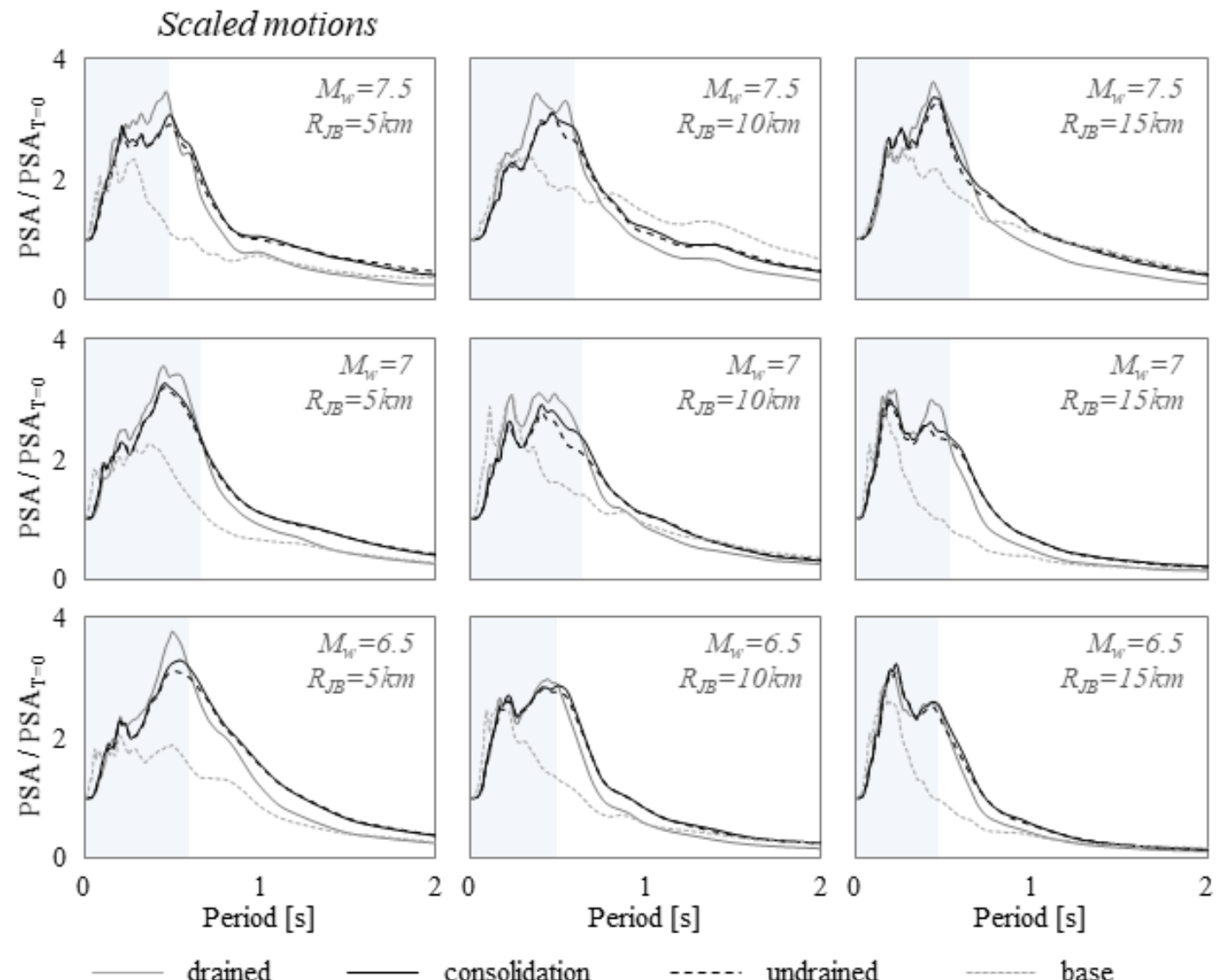

consolidation

undrained

base

\section{Figure 19}

Elastic acceleration response spectra at ground surface (average values) for 9 (Mw, RJB) combination calculated assuming drained, undrained and consolidation conditions during shaking. Mean spectra at the base (only scaled earthquake motions to approximate the target base spectrum) are also included. 

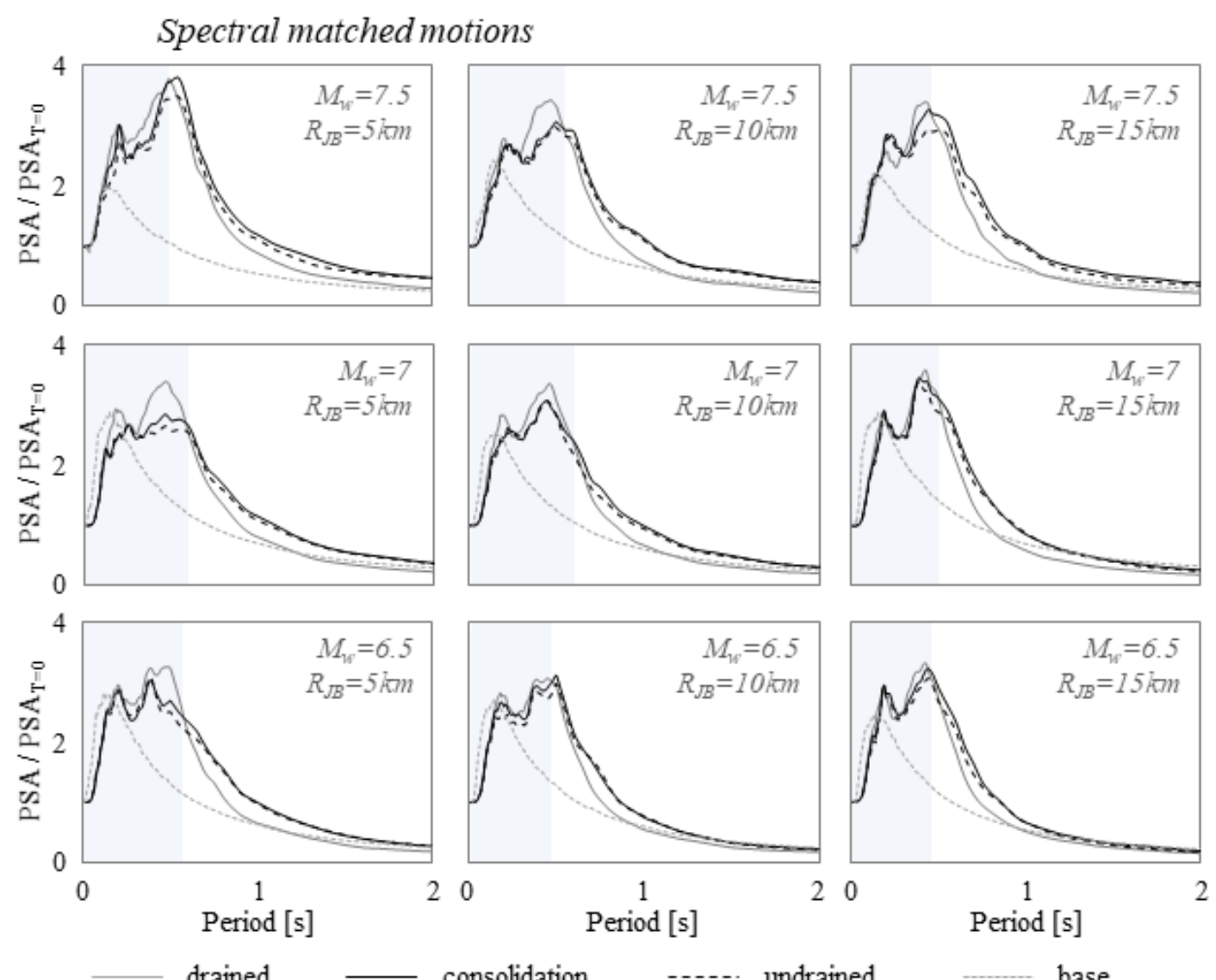

drained

consolidation

undrained

base

\section{Figure 20}

Ground surface elastic response spectra (considering consolidation conditions) normalized to ag, i.e. Se value for $T=0$ at the mean base spectrum, along with their average spectrum.
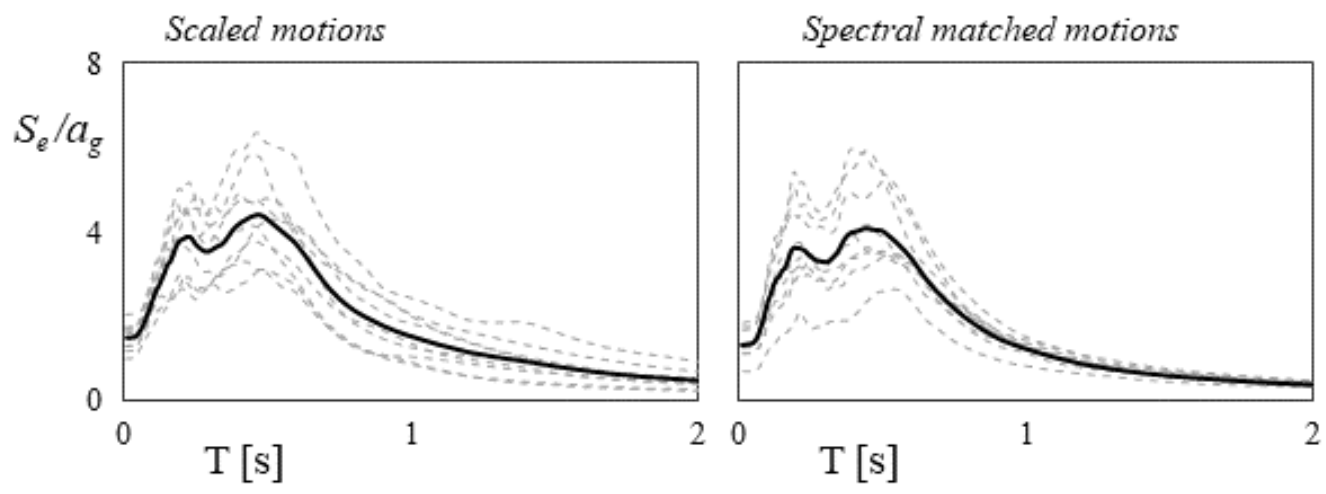

normalized surface elastic spectra for the $9 M_{w}, R_{J B}$ combinations

average spectrum

\section{Figure 21}

Average normalized to ag surface elastic response spectra in comparison with the corresponding base spectra (ground type A). Linearization according to EC8 four-branches elastic spectrum also provided. 


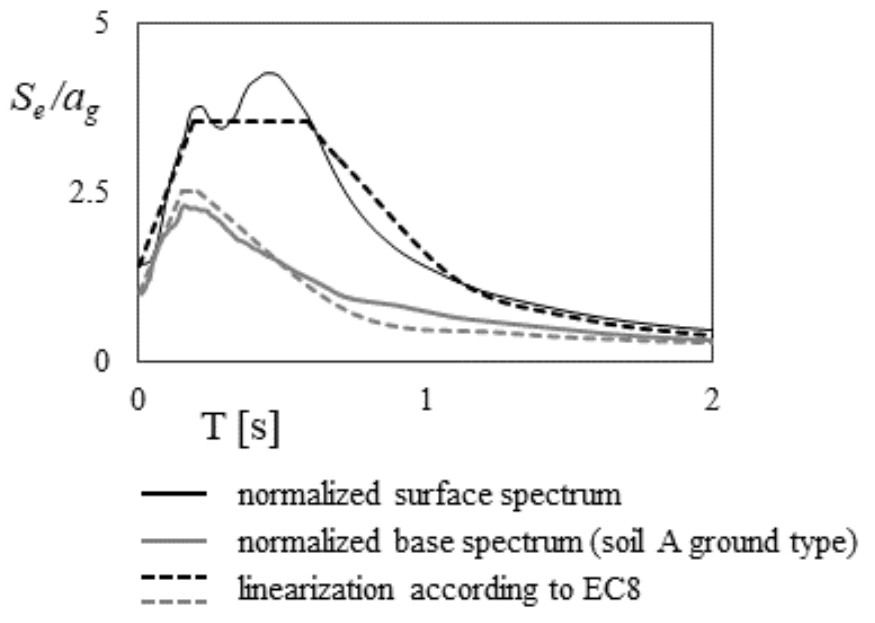

\section{Figure 22}

Average normalized to ag surface elastic response spectra in comparison with the corresponding base spectra (ground type A). Linearization according to EC8 four-branches elastic spectrum also provided.

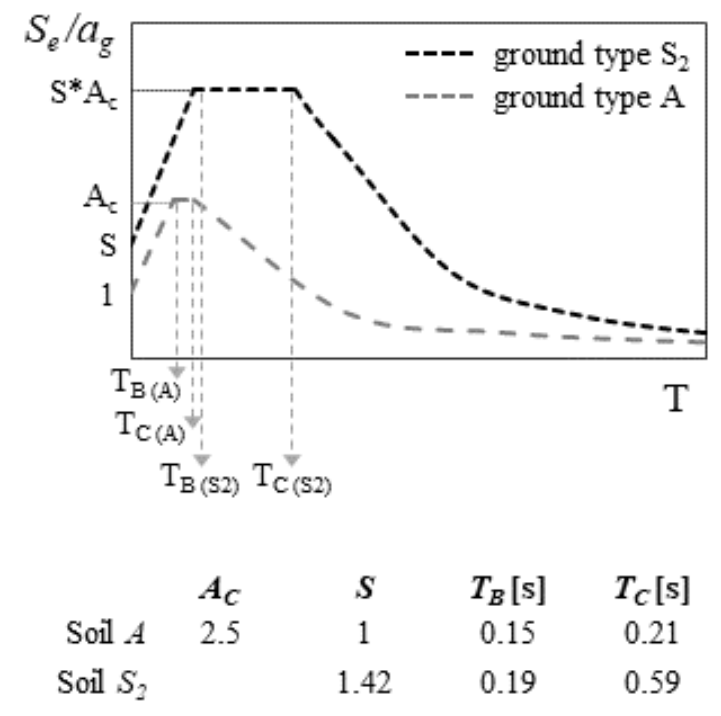

\section{Figure 23}

Selected values of Ac, S, TB, and TC to express the response spectrum at ground type $\mathrm{S} 2$ and ground type A according to EC8 four-branches elastic spectrum. 